\title{
Abnormal expression of SIRTs in psoriasis: Decreased expression of SIRT 1-5 and increased expression of SIRT 6 and 7
}

\author{
XIAOJING FAN ${ }^{1 *}$, KEXIANG YAN $^{2 *}$, QINQIN MENG $^{1}$, RUI SUN ${ }^{3}$,

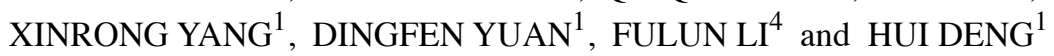 \\ ${ }^{1}$ Department of Dermatology, Shanghai Jiao Tong University Affiliated Sixth People's Hospital, Shanghai 200233; \\ ${ }^{2}$ Shanghai Institute of Dermatology and Department of Dermatology, Huashan Hospital, Fudan University, \\ Shanghai 200040; ${ }^{3}$ Department of Dermatology, Changhai Hospital, Second Military Medical University, \\ Shanghai 200433; ${ }^{4}$ Department of Dermatology, Yueyang Hospital of Integrated Traditional Chinese and Western Medicine, \\ Affiliated with Shanghai University of Traditional Chinese Medicine, Shanghai 200437, P.R. China
}

Received August 10, 2018; Accepted March 19, 2019

DOI: $10.3892 / \mathrm{ijmm} .2019 .4173$

\begin{abstract}
The prevalence of psoriasis is increasing, and poses a serious risk to human health and quality of life. Psoriasis, a chronic immune-mediated skin disease with epidermal hyperkeratosis and parakeratosis, is associated with numerous complications, including metabolic syndromes that are regulated by sirtuins (SIRTs) via deacetylation. As they serve a necessary function in inflammation and metabolism, SIRTs are considered to link inflammation and metabolic syndrome. Previous studies have indicated that SIRTs serve a function in the pathophysiology of psoriasis, but to date no detailed research has been conducted investigating the expression levels and patterns of SIRTs in psoriasis. The present study investigated the abnormal expression of SIRTs in psoriasis and provided a theoretical foundation for the treatment and prognosis of psoriasis. Tumor necrosis factor (TNF)- $\alpha$-stimulated $\mathrm{HaCaT}$ cells and an imiquimod-induced psoriasis mouse model were used to produce in vitro and in vivo models, respectively. Psoriasis clinical specimens (psoriasis area and severity index
\end{abstract}

Correspondence to: Dr Hui Deng, Department of Dermatology, Shanghai Jiao Tong University Affiliated Sixth People's Hospital, 600 Yishan Road, Shanghai 200233, P.R. China

E-mail: denghui_1@hotmail.com

Dr Fulun Li, Department of Dermatology, Yueyang Hospital of Integrated Traditional Chinese and Western Medicine, Affiliated with Shanghai University of Traditional Chinese Medicine, 110 Gan He Road, Shanghai 200437, P.R. China

E-mail: drlifulun@163.com

*Co-first authorship

Abbreviations: SIRTs, sirtuins; IMQ, imiquimod; EGFR, epidermal growth factor receptor; MAPK, mitogen activated protein kinase; NF- $\kappa \mathrm{B}$; nuclear factor- $\kappa \mathrm{B}$

Key words: psoriasis, SIRTs, tumor necrosis factor- $\alpha$, IMQ, metabolic syndrome, inflammation
$>10 ; n=22)$ and normal group specimens $(n=22)$ were obtained from human subjects. The mRNA and protein expression levels in human and mouse skin lesions and TNF- $\alpha$-stimulated HaCaT cells were detected using reverse transcription-quantitative polymerase chain reaction (RT-qPCR) and western blotting, and compared with the control groups. The expression patterns of SIRT proteins were investigated using immunofluorescence (IF) staining. The expression levels of SIRT1, SIRT2, SIRT3, SIRT4 and SIRT5 were downregulated while those of SIRT6 and SIRT7 were upregulated in skin lesions and TNF- $\alpha$-stimulated $\mathrm{HaCaT}$ cells compared with the control group as determined by RT-qPCR, western blotting and IF. Statistically significant differences were observed in vivo and in vitro. P-values of SIRT1-7 mRNA are less than 0.05 in RT-qPCR, and the P-values of SIRT1-7 proteins are less than 0.05 except for SIRT4 in the western blot analysis. SIRTs serve notable functions in severe psoriasis dermatitis, with the overexpression of SIRT6 and SIRT7 potentially induced by the adaptive immune response, and the downregulation of SIRT1, SIRT2, SIRT3, SIRT4 and SIRT5 may be a result of an internal environment imbalance in vivo. Psoriasis is an inflammation and metabolism-associated disease mediated by the SIRT family. The present results provide a novel potential mechanism and strategy for the treatment of psoriasis by modulating the function and expression of SIRTs.

\section{Introduction}

Psoriasis is a chronic autoimmune inflammatory disease with epidermal hyperkeratosis and parakeratosis, and its prevalence rate ranges between 0.09 and $5.1 \%$ globally, with the highest prevalence rate of $5.1 \%$ reported in the USA in 2017 (1). The clinical epidemiological characteristics of psoriasis may vary in different regions and populations. The prevalence of psoriasis in China was revealed to be $0.123 \%$, and had grown to $0.47 \%$ according to a community-based survey conducted in six cities from six provinces in 2010 (2). The pathogenesis of psoriasis is complex, and there are multiple risk factors including smoking, excessive alcohol intake, hypertension, hyperlipidemia, obesity and insulin resistance, which are in turn associated with cardiovascular disease (3). The majority of inflammatory cytokines, 
including tumor necrosis factor (TNF)- $\alpha$ and interferon- $\gamma$ $($ IFN- $\gamma)$, in psoriasis lesions and immune cells, including T helper cell type 1 (Th1) and Th17 in circulation, are increased in patients with psoriasis (4). A previous study demonstrated that psoriasis is associated with numerous types of comorbidities including metabolic syndrome (MS), diabetes, depression and cancer (5), thereby suggesting that psoriasis is an inflammatory and metabolic disease.

The sirtuin (SIRT) family, consisting of seven members (SIRT1-7), are a conserved superfamily of nicotinamide adenine dinucleotide ${ }^{+}$-dependent deacetylases that are involved in the regulation of energy metabolism, aging, cell apoptosis, gene transcription, tumor development, autoimmune inflammation and epigenetics (6). SIRTs serve notable functions in metabolic and inflammatory processes. Associations between pathogenetic pathways and the localizations of SIRT have been reported. The proteins of SIRT1, SIRT6 and SIRT7 are localized in the nucleus, those of SIRT3, SIRT4 and SIRT5 in the mitochondria, and those of SIRT2 in the cytoplasm and/or nucleus (7). SIRT1 is able to regulate inflammation-associated signaling pathways, and inhibit mitochondrial reactive oxygen species (ROS), oxidative stress, mitochondrial DNA mutations and mitochondrial damage to in turn inhibit pancreatic $\beta$-islet cell injury, and subsequently inhibit the occurrence of diabetes mellitus, obesity, insulin resistance and fatty liver disease (8-10). SIRT1, SIRT2 and SIRT6 affect metabolism and longevity by regulating the nuclear factor $-\kappa \mathrm{B}(\mathrm{NF}-\kappa \mathrm{B})$ signaling pathways and fatty acid $\beta$-oxidation $(11,12)$. SIRT3 is able to inhibit proliferation capacity, promote fatty acid $\beta$-oxidation and activate the key enzymes of the electron transport chain and the urea cycle (13). SIRT4 and SIRT5 are able to activate the pyruvate dehydrogenase complex (PDH), succinate dehydrogenase and the glutamate dehydrogenase complex (GDH) to regulate metabolism (14). SIRT7 serves a function in regulating the release of inflammatory cytokines, avoiding DNA damage repair, adapting to environmental challenges and cell survival (15).

Altogether, these studies imply that SIRTs may link metabolism and inflammatory signaling. Furthermore, there have been a number of previous studies $(16,17)$ that have investigated the association between SIRT1, SIRT6 and psoriasis, but to the best of our knowledge the present study is the first to investigate the altered expression of SIRT genes in psoriasis.

\section{Materials and methods}

Cell cultures. HaCaT, the human keratinocyte cell line, purchased from Jiangsu KeyGEN BioTECH Corp., Ltd. (Jiangsu, China), which was grown in the Central Laboratory of Shanghai Sixth People's Hospital Affiliated to Shanghai Jiaotong University (Shanghai, China), and cultured in Dulbecco's modified Eagle's medium (HyClone; GE Healthcare Life Sciences, Logan, UT, USA) supplemented with $10 \%$ heat inactivated fetal bovine serum (Gibco; Thermo Fisher Scientific, Inc., Waltham, MA, USA). All cells were maintained in a humidified incubator at $37^{\circ} \mathrm{C}$ with $5 \% \mathrm{CO}_{2}$.

TNF- $\alpha$-stimulated HaCaT cell model. A number of previous studies had exposed HaCaT cells to $20 \mathrm{ng} / \mathrm{ml} \mathrm{TNF-} \alpha$ for $24 \mathrm{~h}$ and reported that TNF- $\alpha$ serves a notable function in the pathogenesis of psoriasis $(18,19)$. In the present study, a TNF- $\alpha$ (cat. no. H8916; Sigma-Aldrich; Merck KGaA, Darmstadt, Germany)-stimulated HaCaT cell model was used to simulate the environment of keratinocytes in psoriasis. Then, cell viability was assessed using a Cell Counting Kit-8 assay (Beyotime Institute of Biotechnology, Haimen, China) according to the manufacturer's protocol. HaCaT cells were seeded into 96 -well plates $\left(4 \times 10^{3}\right.$ cells per well) and treated with TNF- $\alpha(20 \mathrm{ng} / \mathrm{ml})$ in culture medium without serum for $0,4,8,12,24$ and $36 \mathrm{~h}$ at $37^{\circ} \mathrm{C}$. Absorbance was assessed at $450 \mathrm{~nm}$ with a microplate reader (Omega Bio-Tek, Inc., Norcross, GA, USA). Cells were divided into the following three groups: Treatment, control and blank groups. The control group contained no TNF- $\alpha$, and the blank group contained no TNF- $\alpha$ and HaCaT cells. Other experimental conditions were the same as the treatment group. The most suitable induction time point was determined to be the time point that induced evident changes in cell morphology and relatively greater cell proliferation compared with the control group. The mean optical density (OD) of three wells in each group were used to calculate the percentage of cell proliferation as follows: Cell proliferation $(\%)=\left[\left(\mathrm{OD}_{\text {treatment }}-\mathrm{OD}_{\text {blank }}\right) /\left(\mathrm{OD}_{\text {control }}-\mathrm{OD}_{\text {blank }}\right)\right]$ x100.

Immunofluorescence (IF) examinations. IF staining was performed to assess the expression levels and patterns of theSIRT family of proteins in cells. First, HaCaT cells $\left(2 \times 10^{4}\right.$ cells/well $)$ were inoculated into 24 -well culture plates in which sterile coverslips were placed in advance, until the cells were close to forming a monolayer. The coverslips were then removed, and cells were washed twice with PBS. Following $24 \mathrm{~h}$, cells were treated with $4 \%$ paraformaldehyde for $15 \mathrm{~min}$ at room temperature and $0.1 \%$ Triton $\mathrm{X}-100$ for $25 \mathrm{~min}$ at room temperature. The cells were subsequently blocked with $5 \%$ bull serum albumin (BSA; Bovogen Biologicals Pty., Ltd., Melbourne, VIC, Australia) for $1 \mathrm{~h}$ at room temperature. Cultured HaCaT cells were incubated with the following specific antibodies overnight at $4^{\circ} \mathrm{C}$ : SIRT1 (1:50; cat. no. 13161-1-AP; ProteinTech Group, Inc., Chicago, IL, USA), SIRT2 (1:100; cat. no. PB0174; Wuhan Boster Biological Technology, Ltd., Wuhan, China), SIRT3 (1:100; cat. no. A01061-1; Wuhan Boster Biological Technology, Ltd.), SIRT4 (1:100; cat. no. ab10140; Abcam, Cambridge, MA, USA), SIRT5 (1:100; cat. no. 15122-1-AP; ProteinTech Group, Inc.), SIRT6 (1:100; cat. no. PB0375; Wuhan Boster Biological Technology, Ltd.) and SIRT7 (1:100 cat. no. PB0376; Wuhan Boster Biological Technology, Ltd.). On the following day, cells were incubated for $1 \mathrm{~h}$ at $37^{\circ} \mathrm{C}$ with secondary antibodies: Donkey anti-rabbit immunoglobulin G (IgG; Alexa Fluor 488; 1:500; cat. no. ab150073; Abcam) was used to label SIRT1, SIRT2, SIRT3, SIRT5, SIRT6 and SIRT7, and fluorescein isothiocyanate (FITC)-conjugated donkey anti-goat IgG heavy and light chain $(\mathrm{H}+\mathrm{L} ; 1: 50$; cat. no. GB22404; Wuhan Servicebio Technology Co., Ltd., Wuhan, China) was used to label SIRT4. Stained cells were counterstained with DAPI for $\sim 10 \mathrm{~min}$ at room temperature and visualized using an inverted fluorescence microscope (Olympus Corporation, Tokyo, Japan; magnification, $\mathrm{x} 400$ ).

Animal model. All animal experiments were performed in accordance with the National Institutes of Health Guidelines 
on Laboratory Research (20) and ethically approved by the Animal Welfare Committees of Shanghai Sixth People's Hospital (Shanghai, China). The Animal Experiment Registration number was no. DWLL2017-0312. All eight mice were obtained from the Animal Experiment Center at Shanghai Sixth People's Hospital and bred in specific pathogen-free colony. All mice were housed at $40 \%$ humidity at $25^{\circ} \mathrm{C}$, with a $16 \mathrm{~h}$ light $/ 8 \mathrm{~h}$ dark cycle. All mice had free access to sterile water and sterile food. Imiquimod (IMQ)-induced skin inflammation in mice resembles psoriasis phenotypically and is a well-established technique $(20,21)$. BALB/c female

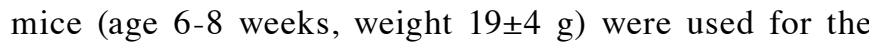
present study. Mice of the same sex were selected to avoid self-reproduction subsequent to group establishment and to provide a stable external environment. Experimental mice received a daily topical dose of $62.5 \mathrm{mg}$ of $5 \%$ IMQ cream (cat. no. H20030128; Sichuan Med-Shine Pharmaceutical Co., Ltd., Sichuan, China) on a $2 \times 2 \mathrm{~cm}$ shaved area on their back for 7 consecutive days. Control mice were treated similarly with normal saline as a control treatment. To score the severity of inflammation on the skin of mouse backs, an objective scoring system was developed based on the clinical psoriasis area and severity index (PASI) (20), consisting of measures of skin erythema, thickness and scales. Each parameter was scored from 0 to 4, where scores $0,1,2,3$ and 4 referred to no clinical signs, slight clinical signs, moderate clinical signs, marked clinical signs and very marked clinical signs, respectively. The cumulative score denotes the severity of inflammation. At the end of the experiment on day 7, all mice were sacrificed by cervical dislocation and skin samples were collected within $2 \mathrm{~h}$ for additional experiments.

Clinical samples. The present study was performed once the patients' written informed consent was obtained by the Department of Dermatology, Shanghai Sixth People's Hospital, and was ethically approved by the Ethics Committee of Shanghai Sixth People's Hospital (approval no. 2018-029). Based on age and sex, a total of 22 clinical psoriasis and 22 normal specimens were divided into two groups. In addition, the condition of each patient with psoriasis was evaluated using the PASI. The inclusion criteria for the psoriasis group were as follows: i) No restrictions on sex and age; ii) psoriasis vulgaris: Scales on the basis of the erythema of the whole body-wax dripping phenomenon, translucent film following scaling-film phenomenon, and puncture hemorrhage following scraping the film, Auspitz phenomenon; iii) pathological diagnosis: Hyperkeratosis, including hyperkeratosis of keratin epithelial tissues, the epidermis extended to the dermis, lymphocytes infiltrated the dermis; and iv) no treatment for recurrence or the initial symptoms. The exclusion criteria for the psoriasis group were as follows: i) Pregnancy and lactation; ii) $\mathrm{PASI}<10$; and iii) patients who have been treated previously. The inclusion criteria for the normal group were as follows: i) Matched with the psoriasis group according to sex, age and surgical site; ii) no skin disease or family history; and iii) PASI=0. The exclusion criteria for the normal group were as follows: i) Pregnancy and lactation; and ii) PASI $\neq 0$. Clinical tissues that had been diagnosed with psoriasis vulgaris (PASI >10) or normal tissues were collected using sterile enzyme-free tubes. The samples were quickly stored in liquid nitrogen to freeze for subsequent use.

Reverse transcription-quantitative polymerase chain reaction (RT-qPCR) analyses. Total RNA of the cells and tissues was extracted using an RNAiso Plus kit (Takara Bio, Inc., Otsu, Japan), and cDNA was synthesized using a PrimeScript ${ }^{\mathrm{TM}}$ RT Reagent kit (cat. no. RR037A; Takara Biotechnology Co., Ltd., Dalian, China). The RT temperature protocol was as follows: Reaction at $37^{\circ} \mathrm{C}$ for $5 \mathrm{~min}$ and RT inactivation at $85^{\circ} \mathrm{C}$ for 5 sec. RT-qPCR reactions $(20 \mu \mathrm{l})$ contained $2 \mu \mathrm{l}$ cDNA, $10 \mu 1$ SYBR-Green (SYBR ${ }^{\circledR}$ Premix Ex TaqTli RNaseH Plus; cat. no. RR420A; Takara Biotechnology Co., Ltd.) and the appropriate primers. All the kits were used according to the manufacturer's protocol. Product accumulation was monitored using SYBR-Green fluorescence with an ABI Prism 7500 Sequence Detection System. The PCR cycling parameters were set as follows: $95^{\circ} \mathrm{C}$ for $30 \mathrm{sec}$ followed by 40 cycles of PCR reactions at $95^{\circ} \mathrm{C}$ for $5 \mathrm{sec}$ and $60^{\circ} \mathrm{C}$ for $1 \mathrm{~min}$. The standard curves of different SIRT family primers indicated the relative expression levels. The primers for GAPDH and $\beta$-actin were used as internal controls for normalization. Finally, the data were analysed using GraphPad Prism 5 (GraphPad Software, Inc., La Jolla, CA, USA). Primers were synthesized by Sangon Biotech Co., Ltd. (Shanghai, China). The primers for human and cellular RT-qPCR are presented in Table I, and the primers for mouse RT-qPCR are presented in Table II. The ratio of fold changes in SIRT mRNA expression was calculated by normalizing the $\mathrm{Cq}$ values of the target gene (SIRT family) to those of the housekeeping genes (GAPDH and $\beta$-actin) and then using the $2^{-\Delta \Delta \mathrm{Cq}}$ method (22) to compare the test groups and calibrator groups. The formulas used were as follows: $\Delta \mathrm{Cq}$ (test) $=\mathrm{Cq}$ (target, test) $\mathrm{Cq}$ (reference, test); $\Delta \mathrm{Cq}$ (calibrator) $=\mathrm{Cq}$ (target, calibrator) $-\mathrm{Cq}$ (reference, calibrator); and $\Delta \Delta \mathrm{Cq}=\Delta \mathrm{Cq}$ (test) $-\Delta \mathrm{Cq}$ (calibrator). The calculation for the expression level rate was $2^{-\Delta \Delta \mathrm{Cq}}=$ the ratio of the expression. $2^{-\Delta \Delta \mathrm{Cq}}$ of the control groups were classified as ' 1 ', and the treatment groups were compared.

Western blotting. Frozen clinical tissue and mouse skin tissue specimens were prepared for protein extraction in advance using a mortar, and then tissue proteins and cellular proteins were extracted on ice using radioimmunoprecipitation assay lysis buffer (cat. no. P0013B; Beyotime Institute of Biotechnology). The amount of protein in the extracts was determined using an Enhanced Bicinchoninic Acid Protein Assay kit (cat. no. P0010; Beyotime Institute of Biotechnology). Following quantitative analysis, equal amounts of protein $(50 \mu \mathrm{g})$ were resolved in 12, 10 and 6\% SDS-PAGE gels and electrotransferred to polyvinylidene difluoride membranes (EMD Millipore, Billerica, MA, USA). Membranes were subsequently blocked with $5 \%$ non-fat milk for $1 \mathrm{~h}$ at room temperature and probed with specific antibodies overnight at $4^{\circ} \mathrm{C}$ against SIRT1 (1:600; cat. no. 13161-1-AP; ProteinTech Group, Inc.), SIRT2 (1:600; cat. no. PB0174; Wuhan Boster Biological Technology, Ltd.), SIRT3 (1:600; cat. no. A01061-1; Wuhan Boster Biological Technology, Ltd.), SIRT4 (1:200, cat. no. ab10140; Abcam), SIRT5 (1:600; cat. no. 15122-1-AP; ProteinTech Group, Inc.), SIRT6 (1:600; cat. no. PB0375; Wuhan Boster Biological Technology, Ltd.), SIRT7 (1:600; 
Table I. Primers used for human reverse transcription-quantitative polymerase chain reaction in the present study.

\begin{tabular}{|c|c|c|c|c|}
\hline Primer & Direction & Sequence, $5^{\prime}$ to $3^{\prime}$ & $\mathrm{Tm},{ }^{\circ} \mathrm{C}$ & Length, bp \\
\hline \multirow[t]{2}{*}{ SIRT1 } & $\mathrm{F}$ & ACGCTGGAACAGGTTGCGGG & 65.9 & 20 \\
\hline & $\mathrm{R}$ & AGCGGTTCATCAGCTGGGCAC & 65.2 & 21 \\
\hline \multirow[t]{2}{*}{ SIRT2 } & $\mathrm{F}$ & TCACACTGCGTCAGCGCCAG & 65.6 & 20 \\
\hline & $\mathrm{R}$ & GGGCTGCACCTGCAAGGAGG & 68.9 & 20 \\
\hline \multirow[t]{2}{*}{ SIRT3 } & $\mathrm{F}$ & AAGTGTTGTTGGAAGTGGAG & 49.9 & 20 \\
\hline & $\mathrm{R}$ & TGTGAAAGAAGAATGGGAGT & 50.4 & 20 \\
\hline \multirow[t]{2}{*}{ SIRT4 } & $\mathrm{F}$ & AGACTCCTTGTGATGACTGG & 55.5 & 20 \\
\hline & $\mathrm{R}$ & AGTACAGCTTTCCGAGTTTC & 52.1 & 20 \\
\hline \multirow[t]{2}{*}{ SIRT5 } & $\mathrm{F}$ & AGCTATATTGTGGCCTGAAG & 53.2 & 20 \\
\hline & $\mathrm{R}$ & CACTTTCTGCACTAACACCA & 55.3 & 20 \\
\hline \multirow[t]{2}{*}{ SIRT6 } & $\mathrm{F}$ & AGTTCGACACCACCTTTGAG & 56.4 & 20 \\
\hline & $\mathrm{R}$ & CGTACTGCGTCTTACACTTG & 53.8 & 20 \\
\hline \multirow[t]{2}{*}{ SIRT7 } & $\mathrm{F}$ & CGTCCGGAACGCCAAATAC & 59.3 & 19 \\
\hline & $\mathrm{R}$ & GACGCTGCCGTGCTGATT & 61.1 & 18 \\
\hline \multirow[t]{2}{*}{ GAPDH } & $\mathrm{F}$ & CGGAGTCAACGGATTTGGTCGTATTGG & 65.8 & 27 \\
\hline & $\mathrm{R}$ & GCTCCTGGAAGATGGTGATGGGATTTCC & 66.9 & 28 \\
\hline
\end{tabular}

F, forward; R, reverse; SIRT, Sirtuin; Tm, melting temperature.

Table II. Primers used for mouse reverse transcription-quantitative polymerase chain reaction in the present study.

\begin{tabular}{|c|c|c|c|c|}
\hline Primer & Direction & Sequence, $5^{\prime}$ to $3^{\prime}$ & $\mathrm{Tm},{ }^{\circ} \mathrm{C}$ & Length, bp \\
\hline \multirow[t]{2}{*}{ SIRT1 } & $\mathrm{F}$ & AGTTCCAGCCGTCTCTGTGT & 58.8 & 20 \\
\hline & $\mathrm{R}$ & GATCCTTTGGATTCCTGCAA & 52.4 & 20 \\
\hline \multirow[t]{2}{*}{ SIRT2 } & $\mathrm{F}$ & TAGACACGCTGGAACGAGTG & 57.2 & 20 \\
\hline & $\mathrm{R}$ & TCTCTTTCATCCAGCCCATC & 54.3 & 20 \\
\hline \multirow[t]{2}{*}{ SIRT3 } & $\mathrm{F}$ & CAGCTACATGCACGGTCTGT & 57.9 & 20 \\
\hline & $\mathrm{R}$ & ACACAATGTCGGGTTTCACA & 54.4 & 20 \\
\hline \multirow[t]{2}{*}{ SIRT4 } & $\mathrm{F}$ & CATCCAGCACATTGATTTCG & 51.7 & 20 \\
\hline & $\mathrm{R}$ & CCAGTCTCTCCCAGTTGCTC & 58.1 & 20 \\
\hline \multirow[t]{2}{*}{ SIRT5 } & $\mathrm{F}$ & CATCACCCAGAACATTGACG & 53.7 & 20 \\
\hline & $\mathrm{R}$ & ACAGTGCCACACGAGGTACA & 59.0 & 20 \\
\hline \multirow[t]{2}{*}{ SIRT6 } & $\mathrm{F}$ & GTGGATGAGGTGATGTGCAG & 56.2 & 20 \\
\hline & $\mathrm{R}$ & TCAGCCTTGAGTGCTACTGG & 57.1 & 20 \\
\hline \multirow[t]{2}{*}{ SIRT7 } & $\mathrm{F}$ & GACTGAGCGTACTGCCCTTC & 58.5 & 20 \\
\hline & $\mathrm{R}$ & TTCAGAGGCTGCCCTAATGT & 56.1 & 20 \\
\hline \multirow[t]{2}{*}{$\beta$-actin } & $\mathrm{F}$ & GGCTGTATTCCCCTCCATCG & 60.0 & 20 \\
\hline & $\mathrm{R}$ & CCAGTTGGTAACAATGCCATGT & 59.4 & 22 \\
\hline
\end{tabular}

F, forward; R, reverse; SIRT, Sirtuin; Tm, melting temperature.

cat. no. PB0376; Wuhan Boster Biological Technology, Ltd.), GAPDH $(1: 2,000$; cat. no. GB11002; Wuhan Servicebio Technology Co., Ltd.) and $\beta$-actin (1:1,000; cat. no. ab8226; Abcam). Following three washes with PBS with Tween-20, membranes were incubated with the following secondary antibodies for about $1.5 \mathrm{~h}$ at room temperature: Horseradish peroxidase (HRP)-labeled goat anti-rabbit IgG (H+L; 1:800; cat. no. A0208; Beyotime Institute of Biotechnology) was used to detect SIRT1, SIRT2, SIRT3, SIRT5, SIRT6, SIRT7 and
GAPDH, HRP-labeled Donkey Anti-Goat IgG (H+L; 1:15,00; cat. no. A0181; Beyotime Institute of Biotechnology) was used to detect SIRT4, and HRP-labeled Goat Anti-Mouse IgG (H+L; 1:1,000; cat. no. A0216; Beyotime Institute of Biotechnology) was used to detect $\beta$-actin. Immunoreactive signals were detected using enhanced chemiluminescence reagents (EMD Millipore). Protein expression levels were compared with the control group. Finally, the protein strips were analysed using ImageJ (1.46r/Java 1.6.0_20(32-bit); National Institutes 
A
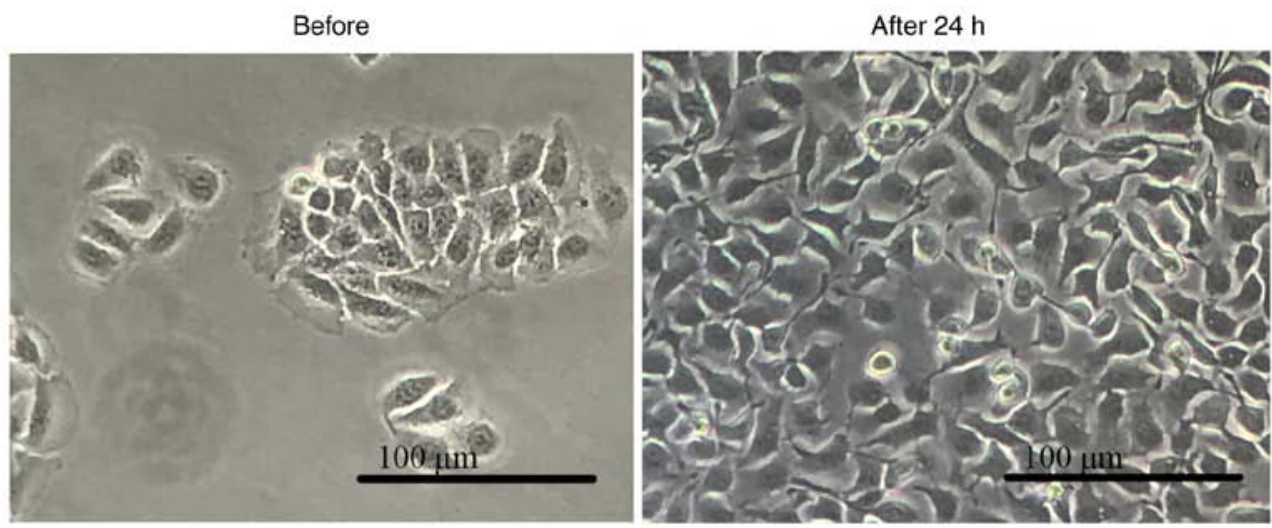

B
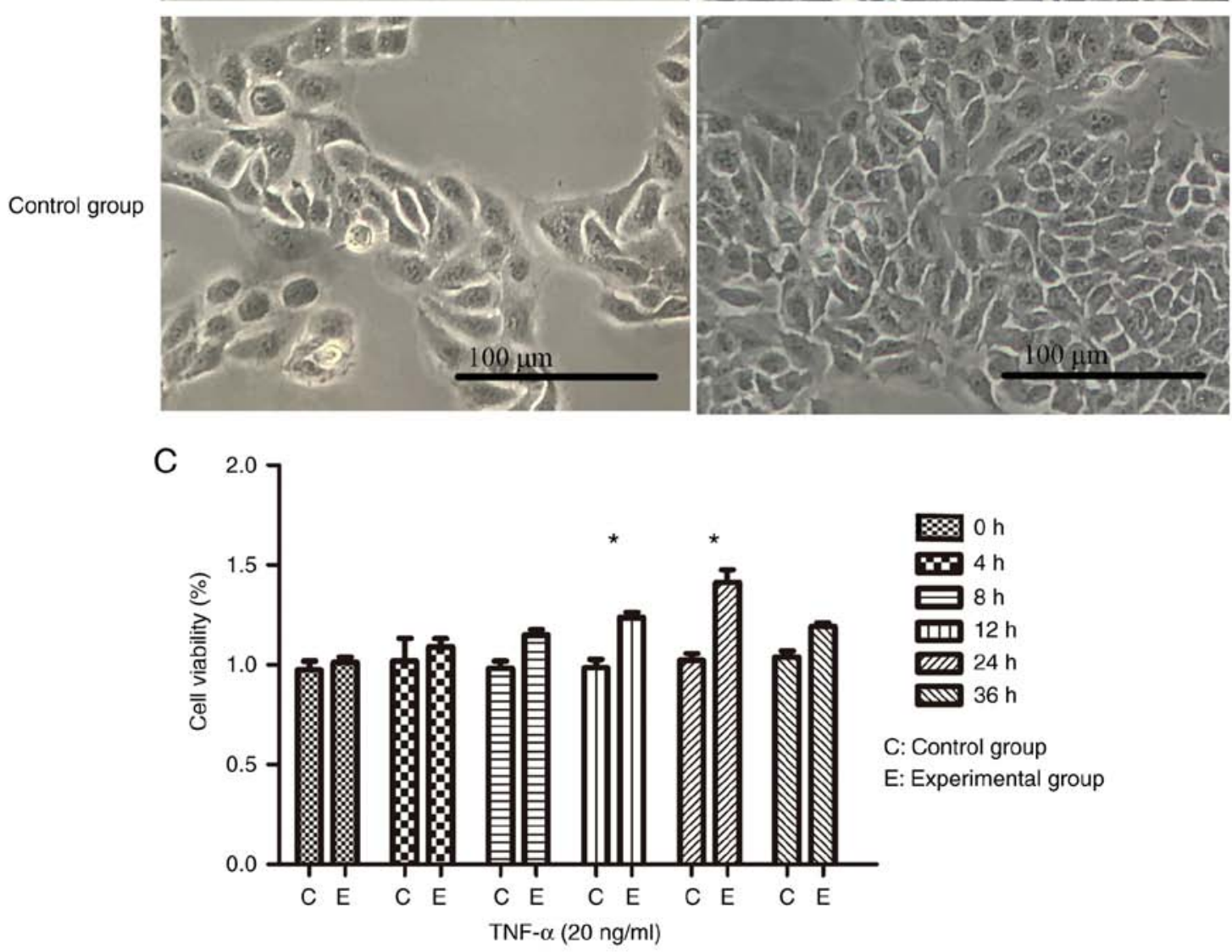

Figure 1. TNF- $\alpha$-stimulated HaCaT cells. (A) TNF- $\alpha$ was used to stimulate HaCaT cells for $24 \mathrm{~h}$ at a concentration of $20 \mathrm{ng} / \mathrm{ml}$. Clearly irregular shapes, a large intercellular space and loose cells were observed, in addition to the increased levels of cell proliferation. (B) Cultured cells without any direct treatment. The cells were tightly connected, few in number and exhibited regular cell morphology when compared with cells stimulated with TNF- $\alpha$. (C) Cell viability test. The calculated percentage of cell proliferation using optical density values revealed that the highest rate of cell proliferation was at $24 \mathrm{~h}$. Data are presented as the mean \pm standard deviation, $\mathrm{n}=3$ per time point. ${ }^{*} \mathrm{P}<0.05$ vs. the control group without TNF- $\alpha$. TNF- $\alpha$, tumor necrosis factor- $\alpha$.

of Health, Bethesda, MD, USA) and GraphPad Prism 5 (GraphPad Software, Inc., La Jolla, CA, USA).

Histopathological and IF examinations. Tissues obtained from patients with diagnosed psoriasis $(\mathrm{n}=22$; PASI $>10)$ and the control patients $(\mathrm{n}=22)$ and the skin samples from the back lesions of mice $(\mathrm{n}=8)$ were fixed at room temperature in $10 \%$ formalin and embedded in paraffin. For histopathological examinations, $4-\mu \mathrm{m}$ sections were stained with hemotoxylin and eosin (H\&E) and observed under an XDS-1B light microscope (Olympus Corporation; magnification, x100). For H\&E staining, sections were dewaxed and dehydrated by washing three times in xylene for 10 min each time, and washing in a descending alcohol gradient of 100, 95, 85 and 75\% ethanol for $10 \mathrm{~min}$ each time. The sections were subsequently stained for $10 \mathrm{~min}$ in $\mathrm{H}$ solution and $3 \mathrm{~min}$ in E solution at room temperature. The sections were dehydrated in 85,95 and $100 \%$ ethanol for 2 min each time, and sealed slides with neutral balsam. For IF staining, $4-\mu \mathrm{m}$ sections were dewaxed three times (10 min each time) with xylene and rehydrated four times ( 3 min each time) with alcohol (in a descending concentration gradient; 100, 95, 90 and 70\%), quenched with endogenous peroxidase, and subsequently treated for antigen retrieval (saline sodium citrate; $\mathrm{pH}=6.0$; water bath heating; $\left.100^{\circ} \mathrm{C} ; 20 \mathrm{~min}\right)$. The sections were then rinsed three times (5 min each time) with PBS following each step. The sections were subsequently blocked with 5\% BSA for $1 \mathrm{~h}$ at room temperature. The antibodies against SIRT1 (1:100; 


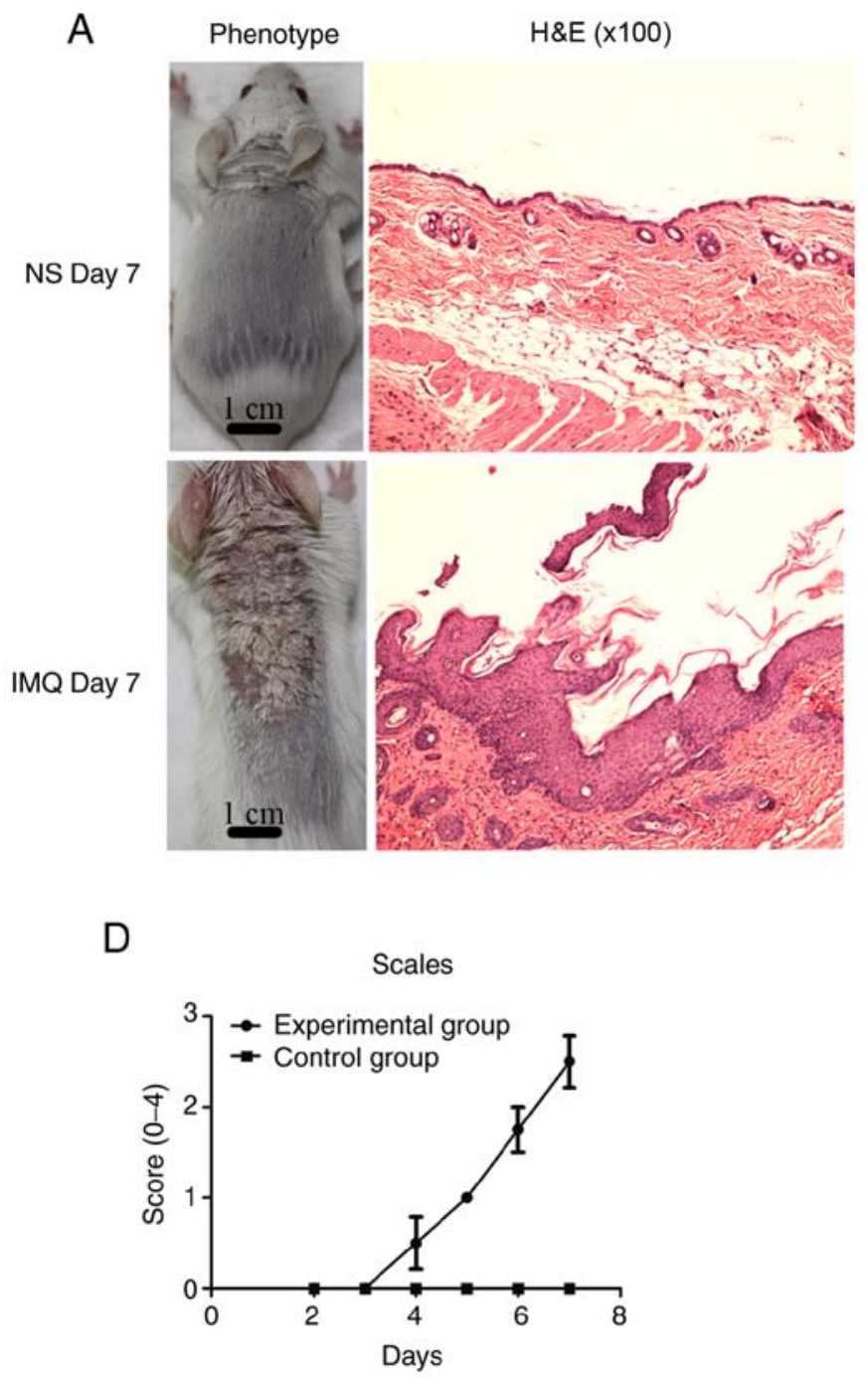

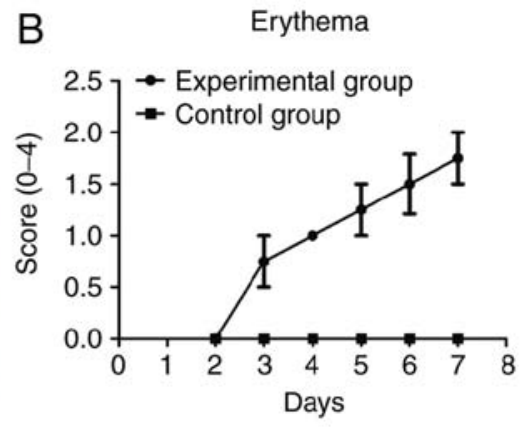

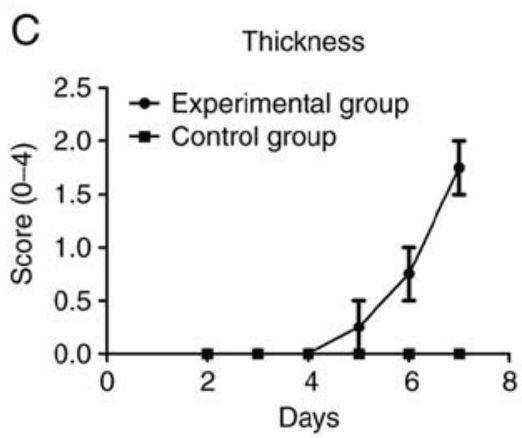

E

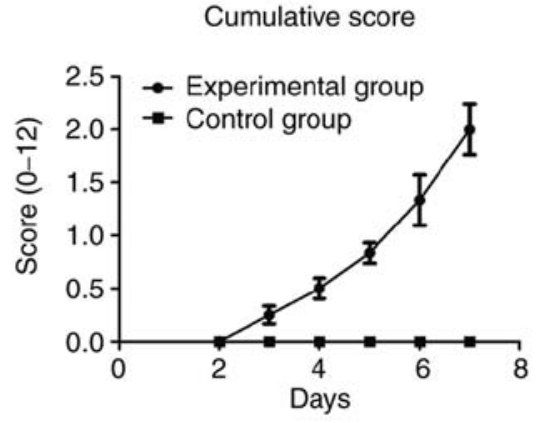

Figure 2. Psoriasis model in mouse skin induced by IMQ. (A) Treatment and control groups. Histological analysis (magnification, x100) revealed epidermal thickening, cuticle hyperkeratosis with parakeratosis, papillary epidermis extending subcutaneously, increased subcutaneous lymphocytes and increased lymphocytes around the blood vessels in the treatment group when compared with the control group. (B) Clinical scores for erythema, (C) skin thickness, (D) scaling and (E) cumulative scores. Data are presented as the mean \pm standard deviation ( $\mathrm{n} \geq 3$ per experiment). IMQ, imiquimod; H\&E, haemotoxylin and eosin; NS, normal saline.

cat. no. 13161-1-AP; ProteinTech Group, Inc.), SIRT2 (1:100; cat. no. PB0174; Wuhan Boster Biological Technology, Ltd.), SIRT3 (1:100; cat. no. A01061-1; Wuhan Boster Biological Technology, Ltd.), SIRT4 (1:100; cat. no. ab10140; Abcam), SIRT5 (1:100; cat. no. 15122-1-AP; ProteinTech Group, Inc.), SIRT6 (1:100; cat. no. PB0375; Wuhan Boster Biological Technology, Ltd.) and SIRT7 (1:100; cat. no. PB0376; Wuhan Boster Biological Technology, Ltd.) were incubated with the sections overnight at $4^{\circ} \mathrm{C}$. On the subsequent day, donkey anti-rabbit IgG (Alexa Fluor 488; 1:500; cat. no. ab150073; Abcam) was used to label SIRT1, SIRT2, SIRT3, SIRT5, SIRT6 and SIRT7, and FITC-conjugated donkey anti-goat IgG (H+L; 1:50; cat. no. GB22404; Wuhan Servicebio Technology Co., Ltd.) was used to label SIRT4 for $1 \mathrm{~h}$ at room temperature. DAPI was used for $10 \mathrm{~min}$ at room temperature to stain nuclei and the cells were observed using a fluorescent microscope (Olympus Corporation; magnification, x400).

Statistical analysis. As the data were normally distributed, a Student's t-test was used to compare the expression levels of the 7 SIRTs between the experiment and control groups. All data are presented as the mean \pm standard deviation and were analysed by Student's t-test using GraphPad Prism 5 (GraphPad Software, Inc.). All statistical tests were two-sided. $\mathrm{P}<0.05$ was considered to indicate a statistically significant difference.

\section{Results}

TNF- $\alpha$-stimulated HaCaT cells. The most noticeable observed changes were in the morphology, the intercellular space and the quantity of cells (Fig. 1A and B). Under culture conditions with TNF- $\alpha(20 \mathrm{ng} / \mathrm{ml})$, cell viability assays revealed that the maximum number of cells was at the $24 \mathrm{~h}$ mark, with a higher number of cells in the experiment group compared with the control group observed at all time points (Fig. 1C).

Animal model. In the present study, compared with the control group, psoriasis-like lesions, including erythema, thickening and scales (Fig. 2A), were gradually observed on the back 
Table III. Patient clinical information.

\begin{tabular}{|c|c|c|c|c|c|c|}
\hline \multirow[b]{2}{*}{ No. } & \multicolumn{2}{|c|}{ Age, years } & \multirow[b]{2}{*}{ Sex } & \multirow[b]{2}{*}{ Site } & \multicolumn{2}{|c|}{ PASI } \\
\hline & Psoriasis & Control & & & Psoriasis & Control \\
\hline 1 & 45 & 41 & $\mathrm{~F}$ & Leg & 10.2 & 0 \\
\hline 2 & 35 & 30 & $\mathrm{~F}$ & Back & 14.8 & 0 \\
\hline 3 & 57 & 53 & $\mathrm{~F}$ & Chest & 15 & 0 \\
\hline 4 & 17 & 14 & $\mathrm{~F}$ & Back & 16 & 0 \\
\hline 5 & 23 & 24 & $\mathrm{~F}$ & Chest & 13.6 & 0 \\
\hline 6 & 56 & 61 & $\mathrm{~F}$ & Arm & 22.8 & 0 \\
\hline 7 & 47 & 59 & $\mathrm{~F}$ & Back & 13 & 0 \\
\hline 8 & 37 & 41 & $\mathrm{~F}$ & Leg & 19.8 & 0 \\
\hline 9 & 55 & 52 & $\mathrm{~F}$ & Leg & 11.4 & 0 \\
\hline 10 & 38 & 35 & $\mathrm{M}$ & Arm & 11.2 & 0 \\
\hline 11 & 31 & 30 & $\mathrm{M}$ & Back & 14.4 & 0 \\
\hline 12 & 30 & 30 & $\mathrm{M}$ & Arm & 10.8 & 0 \\
\hline 13 & 23 & 29 & $\mathrm{M}$ & Chest & 14.6 & 0 \\
\hline 14 & 29 & 29 & $\mathrm{M}$ & Back & 15 & 0 \\
\hline 15 & 54 & 41 & $\mathrm{M}$ & Arm & 15.8 & 0 \\
\hline 16 & 60 & 62 & M & Leg & 10.6 & 0 \\
\hline 17 & 67 & 62 & $\mathrm{M}$ & Leg & 10.2 & 0 \\
\hline 18 & 62 & 62 & $\mathrm{M}$ & Leg & 16 & 0 \\
\hline 19 & 29 & 26 & $\mathrm{M}$ & Back & 16.2 & 0 \\
\hline 20 & 44 & 42 & $\mathrm{M}$ & Leg & 13 & 0 \\
\hline 21 & 38 & 36 & $\mathrm{M}$ & Back & 15.4 & 0 \\
\hline 22 & 64 & 63 & $\mathrm{M}$ & Arm & 10.6 & 0 \\
\hline Mean $\pm \mathrm{SD}$ & $43 \pm 15$ & $42 \pm 15$ & NA & NA & $14.1 \pm 3.1$ & 0 \\
\hline
\end{tabular}

F, female; M, male; SD, standard deviation; PASI, psoriasis area and severity index.

skin of the mice over the 7 days of IMQ treatment. The skin lesions in the mice were confirmed by corresponding histological analyses (H\&E staining; Fig. 2A). To record the skin changes in the mice, an objective scoring system was developed based on PASI, which consists of measurements of skin erythema, thickness and scales. The clinical scores included erythema (Fig. 2B), skin thickness (Fig. 2C), scaling (Fig. 2D), and cumulative scores (Fig. 2E). Compared with the control group, the skin lesions in the experimental group were red and edematous, with more scales and a thickened epidermis. The cumulative score denotes the severity of inflammation.

Clinical data. A total of 44 samples were collected in the present study, including 22 from patients diagnosed with psoriasis vulgaris (PASI>10) and 22 from normal control subjects. All clinical information is presented in Table III. The mean ages were $43 \pm 15$ and $42 \pm 15$ years in the psoriasis and control groups, respectively. The mean PASI score in the psoriasis group was $14.1 \pm 3.1$.

Altered expression of SIRTs in TNF- $\alpha$-stimulated HaCaT cells, IMQ-induced psoriasis-like skin lesions in mice, and clinical psoriasis skin lesions. RT-qPCR was used to evaluate the mRNA expression levels of SIRTs in skin lesions and
TNF- $\alpha$-stimulated HaCaT cells compared with the control groups. The results demonstrated that the mRNA expression levels of SIRT1, SIRT2, SIRT3, SIRT4 and SIRT5 significantly decreased; however, the mRNA expression levels of SIRT6 and SIRT7 significantly increased compared with the control groups $(\mathrm{P}<0.05$; Fig. 3$)$. To confirm this observation, the present study performed western blotting with skin tissues and cells to investigate the protein expression levels. The significantly lower protein expression levels of SIRT1, SIRT2, SIRT3, SIRT4 and SIRT5 and the significantly higher expression levels of SIRT6 and SIRT7 were observed in skin lesions and TNF- $\alpha$-stimulated HaCaT cells when compared with the control groups $(\mathrm{P}<0.05$; except for SIRT4), and were indicative of their potential function in regulating psoriasis dermatitis and psoriasis-like inflammation (Fig. 4).

IF assays. Comparisons of IMQ-induced psoriasis-like skin lesions in mice and clinical psoriasis skin lesions in the control groups based on DAPI staining revealed that the number of epidermal and subcutaneous cells was increased under pathological conditions. In addition, based on the results of FITC and Alexa Fluor-488 staining, the binding sites of the SIRT antibodies were mainly located in the epidermis. Therefore, the expression of SIRT proteins was revealed to be mainly 

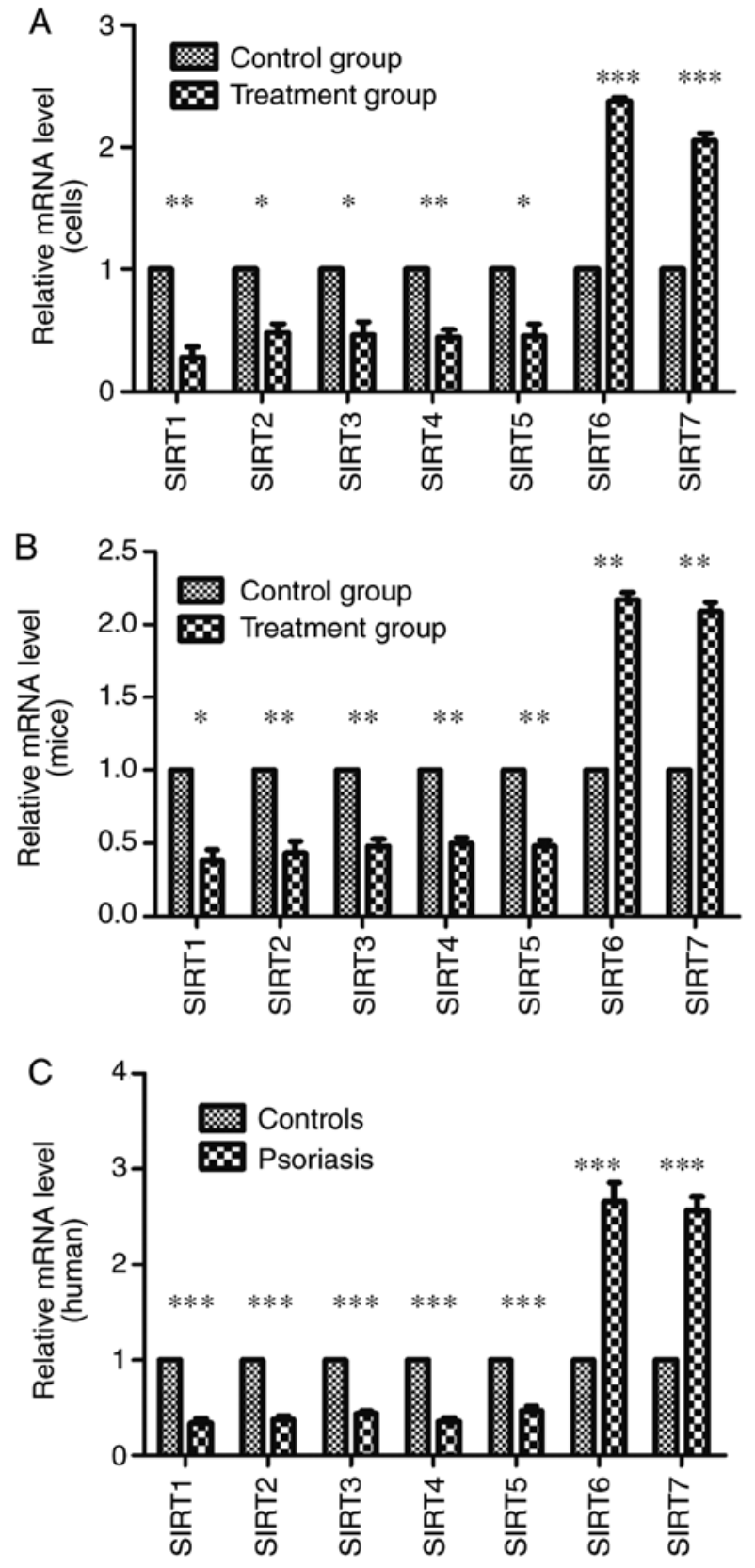

Figure 3. mRNA expression levels of SIRTs determined by reverse transcription-quantitative polymerase chain reaction in (A) cells, (B) mouse tissue and (C) human tissue. The expression levels of SIRT1, SIRT2, SIRT3, SIRT4 and SIRT5 in the experimental groups/patients with psoriasis were significantly reduced and those of SIRT6 and SIRT7 were significantly increased compared with the control groups. Error bars present the standard deviation. ${ }^{*} \mathrm{P}<0.05,{ }^{* *} \mathrm{P}<0.01$ and ${ }^{* * * *} \mathrm{P}<0.001$ vs. the control group. SIRT, Sirtuin.

in the epidermis instead of in the subcutaneous tissue, as presented in Figs. 5 and 6. Notably, IF was negative for SIRT1, SIRT2, SIRT3, SIRT4 and SIRT5 antibodies (Figs. 5A-E, 6A-E and 7A-E), and positive for SIRT6 (Figs. 5F, 6F and 7F) and SIRT7 (Figs. 5G, 6G and 7G) antibodies. Additionally, another function of IF was to identify the localization of SIRTs. SIRT1 and SIRT2 were localized in the nucleus and also the cytoplasm (Fig. 7A and B). SIRT3, SIRT4, and SIRT5 were primarily mitochondrial proteins (Fig. 7C-E). However, SIRT6 and SIRT7 were nuclear SIRTs (Fig. 7F and G). These results are consistent with previous literature (7).

\section{Discussion}

Psoriasis is a chronic autoimmune inflammatory disease associated with multiple epithelial metabolism disorders regulated by the interactions between keratinocytes, dendritic cells and T lymphocytes (23). The skin, as the first line of defense of the body, participates in innate immune responses by activating surface receptors including Toll-like receptors (TLRs) and Nod-like receptors (24). IMQ, a TLR activator, induces cytokine (TNF- $\alpha$ and IFN- $\alpha / \beta$ ) release (20). Keratinocytes, as nonprofessional antigen-presenting cells, may cause skin immune responses through TLRs and major histocompatibility complex (MHC) class II molecules in inflammatory conditions, resulting in the release of inflammatory molecules and cell adhesion molecules by various signaling pathways $(25,26)$. This process may be regulated by SIRTs. In turn, these inflammatory molecules and cell adhesion molecules exert their function on keratinocytes to regulate the growth and differentiation of keratinocytes. This process is also regulated by SIRTs (27). TNF- $\alpha$ is a core cytokine in the development of psoriasis as it cannot react only with keratinocytes or $\mathrm{HaCaT}$ cells to induce immune responses, but also promote the expression of inhibitor of apoptosis protein (IAP), intracellular adhesion molecule (ICAM-1), epidermal growth factor receptors (EGFRs) and keratin 17 (K17) $(19,20)$. TNF- $\alpha$-treated keratinocytes increase the production of EGFR ligands through the classical mitogen activated protein kinase (MAPK) and NF- $\mathrm{KB}$ signaling pathways; thus, EFGR activation may promote epidermal proliferation and inflammatory factor release $(18,19,28)$. Therefore, TNF- $\alpha$-induced $\mathrm{MAPK} / \mathrm{NF}-\mathrm{\kappa B}$ activation may result in cell proliferation and inflammatory responses in $\mathrm{HaCaT}$ cells similar to psoriasis-induced inflammation in vivo. Keratinocytes activate innate immune responses that promote the expression of effective pro-inflammatory factors (including TNF- $\alpha$ ), which may react with keratinocytes to promote the expression of other factors including MHC-II, K17 and IAPs (29). IAP, K17 and ICAM-1, produced via the regulation of TNF- $\alpha$, may cause the epithelial layer to thicken and become difficult to shed, while SIRTs modulate inflammatory factor generation $(16,30)$. These processes may be regulated by SIRTs. IF in the present study revealed that SIRTs were mainly localized in the epithelial layer as opposed to in the subcutaneous tissue, which may mean that keratinocytes, as antigen-presenting cells, may primarily cause the immune response rather than subcutaneous lymphocytes.

SIRTs serve important functions in the mechanisms underlying psoriasis. Numerous studies have reported associations between SIRTs and longevity, insulin resistance and oxidative stress, indicating that SIRTs have a close association with MS $(3,26,31)$. The inflammatory factor production and immune cell differentiation processes are regulated by SIRTs via deacetylation. In addition, accumulating evidence has suggested that the sequential course of inflammation is associated with metabolism via SIRTs $(26,32)$. Therefore, SIRTs may have a close association with psoriasis, causing inflammatory lesions through multiple different pathways.

SIRT1 serves a notable function in survival, differentiation, metabolism and chromatin remodeling. SIRT1 controls immune responses by causing P65, P53, transcription factor 


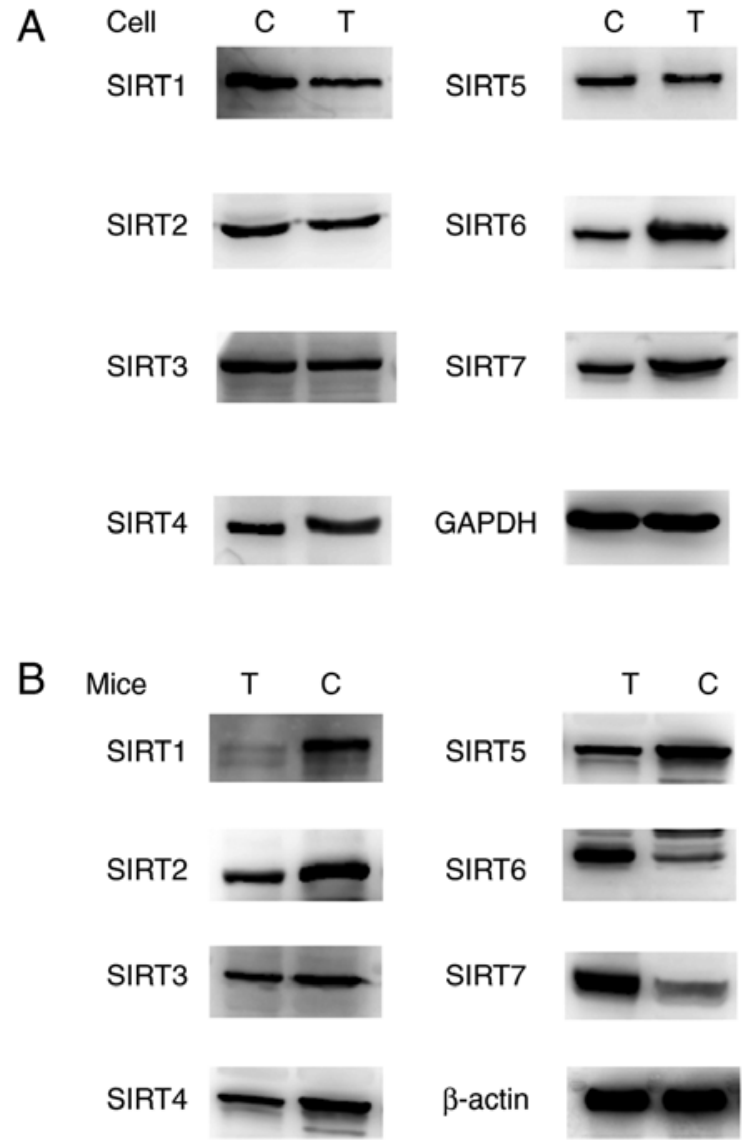

C Clinic

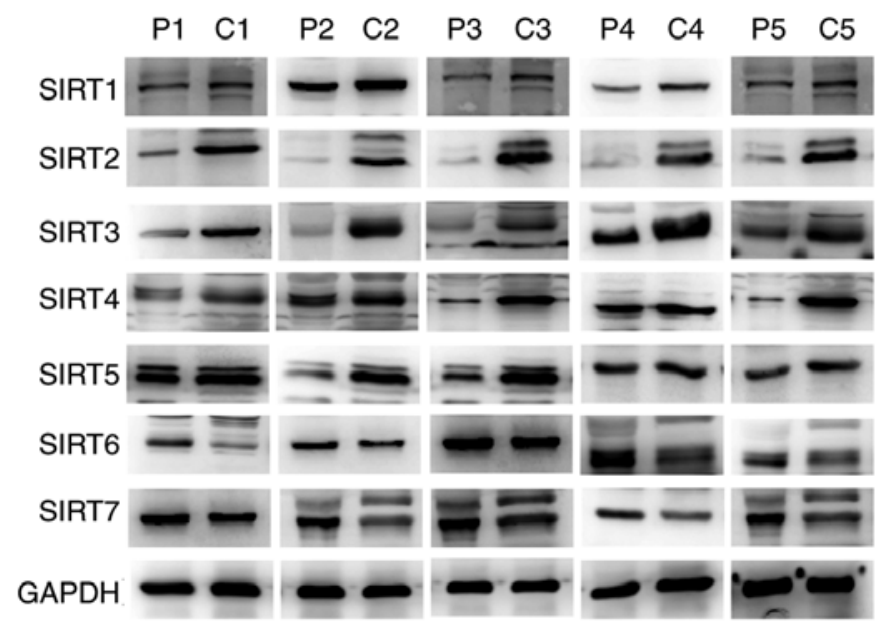

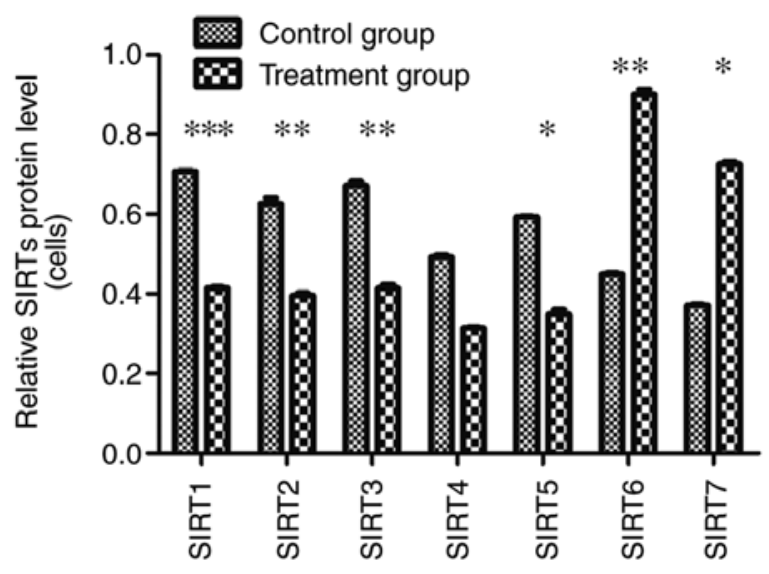
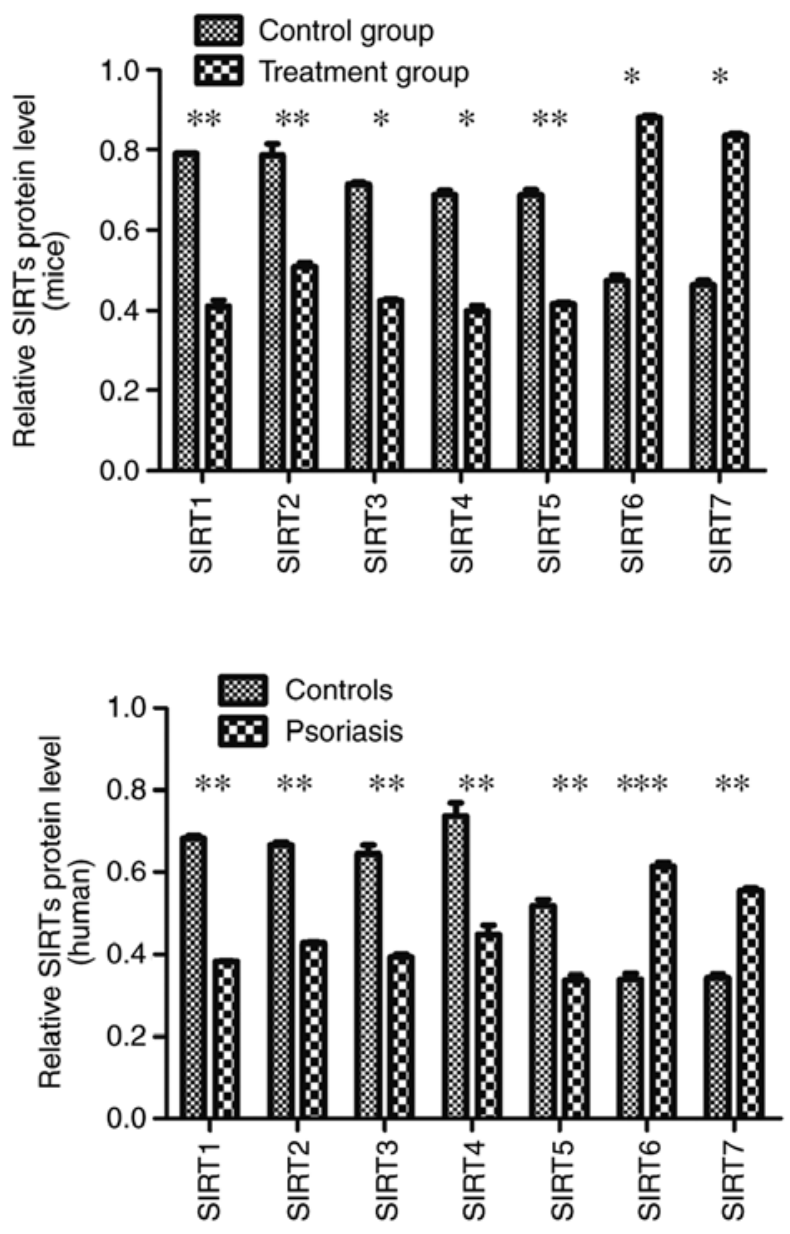

Figure 4. Protein expression levels of SIRTs determined by western blotting in (A) cells, (B) mouse tissue and (C) human tissue. The protein expression levels of SIRT1, SIRT2, SIRT3, SIRT4 and SIRT5 in the experimental groups/patients with psoriasis were significantly reduced and those of SIRT6 and SIRT7 were significantly increased compared with the controls. Error bars present the standard deviation. ${ }^{*} \mathrm{P}<0.05,{ }^{* *} \mathrm{P}<0.01$ and ${ }^{* * *} \mathrm{P}<0.001$ vs. the control group. SIRT, Sirtuin.

activator protein 1, c-Jun, Forkhead box O (FOXO), protein kinase $\mathrm{B}$ and eukaryotic translation initiation factor $2 \mathrm{~A}$ on Lys-141 (K141) and Lys-143 (K143) to deacetylate, which in turn regulates inflammatory factors including nitric oxide, TNF- $\alpha$, interleukin (IL)-12, arginase, TNF- $\beta$ and IL-10; these serve key functions in the pathogenesis of psoriasis and regulate insulin sensitivity $(3,8)$. SIRT1 attenuates inflammation and oxidative stress via the inhibition of mitochondrial ROS production and the reduction of hydrogen peroxide levels at the cardiovascular level (33). The production of ROS may cause mitochondrial DNA mutations, insulin resistance and mitochondrial damage, which ultimately induce diabetes, obesity and fatty liver disease (9). In addition, obesity-induced insulin resistance and type 2 diabetes mellitus, potentially stimulated by chronic inflammation to influence insulin secretion in pancreatic $\beta$ cells, are associated with SIRT1 (10). Notably, SIRT1 positively binds with FOXO3a and nuclear respiratory factor 1 in the promoter region of SIRT6 to form a complex that 
Clinical samples:
DAPI

A SIRT1
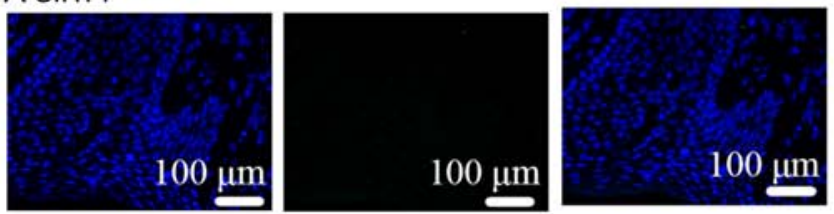

\section{B SIRT2}
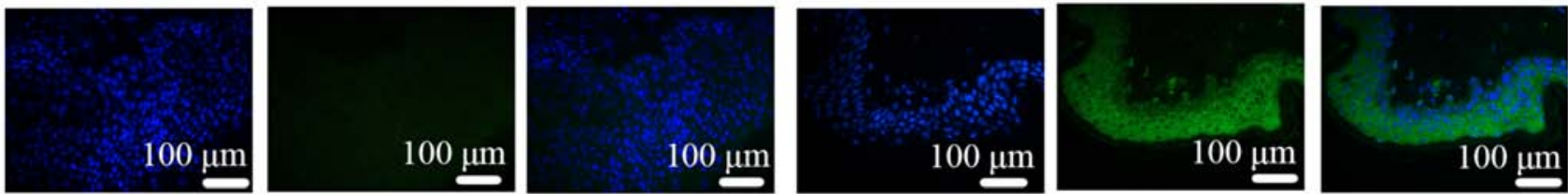

C SIRT3
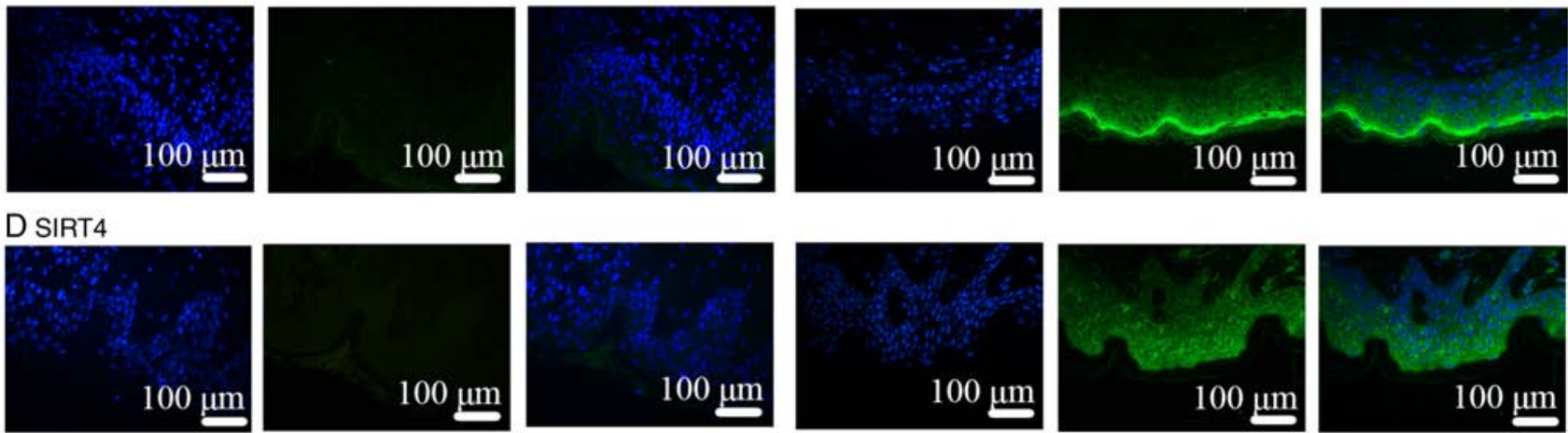

E SIRT5
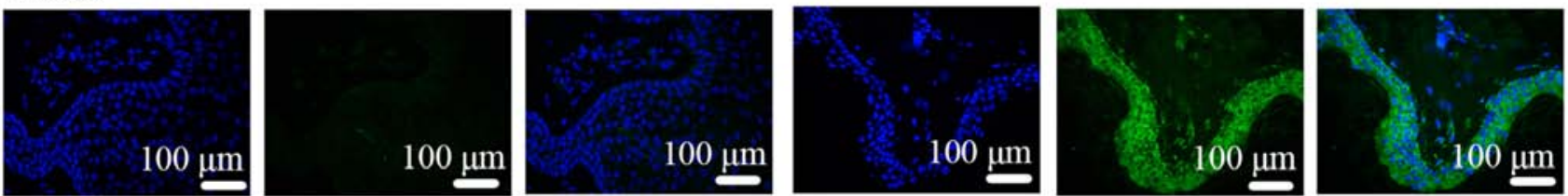

F SIRT6
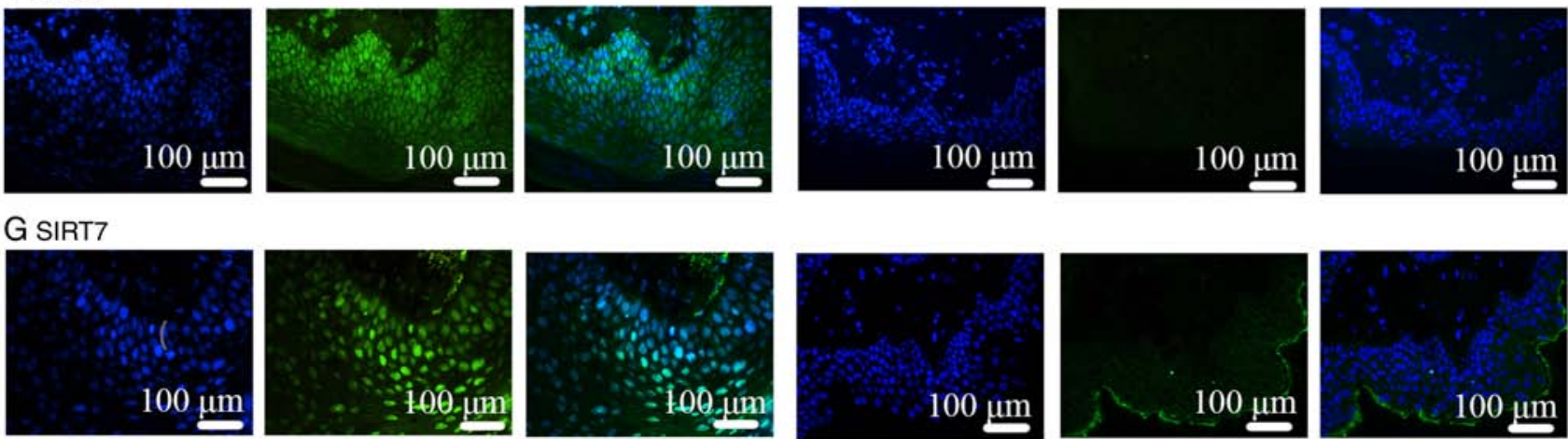

Figure 5. IF in human skin lesions. IF in human psoriasis skin lesions was negative for (A) SIRT1, (B) SIRT2, (C) SIRT3, (D) SIRT4 and (E) SIRT5 antibodies. Lesions were positive for (F) SIRT6 and (G) SIRT7 antibodies. SIRTs were mainly observed in the epithelial layer. IF, immunofluorescence; SIRT, Sirtuin; FITC, fluorescein isothiocyanate.

is associated with longevity and metabolism (11). Furthermore, SIRT1 and SIRT6 alter glycolysis to fatty acid $\beta$-oxidation for the rapid production of a high energy supply and a timely inflammatory response to promote mitochondrial biogenesis and recover homeostasis (33). SIRT6, which predominately mediates metabolism, aging, cancer, DNA repair and genomic stability, affects TNF- $\alpha$ production via the deacetylation of H3K9-Ac in the promoter region of NF- $\kappa B$ target genes (33). The NF- $\mathrm{KB}$ protein complex, a key regulator of the immune response, and TNF- $\alpha$, a common inflammatory pathway cytokine, are involved in a number of inflammatory skin diseases including psoriasis (34). However, whether SIRT6 suppresses the expression of pro-inflammatory cytokines and transcriptional activity depends on the cell type and the transcriptional pathway (11). Therefore, chronic inflammation is stimulated by the activation of c-Jun-dependent transcription and the enhanced expression of pro-inflammatory genes in the livers of Sirt6-null (Sirt6-/-) mice, and SIRT6 is elevated in psoriasis 
$\begin{array}{cc} & \text { Treatment group } \\ \text { DAPI } & \text { Fluo488/FITC }\end{array}$

\section{A SIRT1}
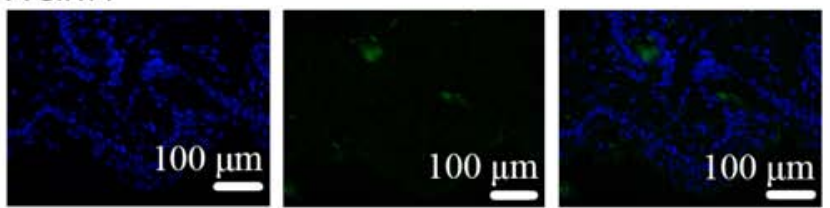

B SIRT2
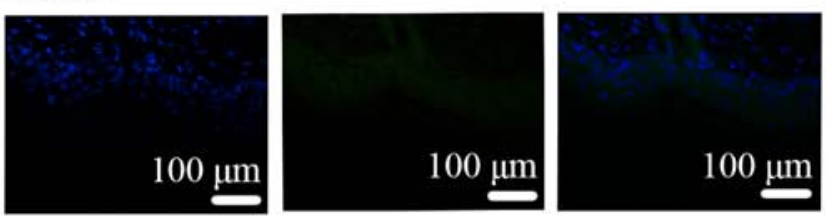

C SIRT3
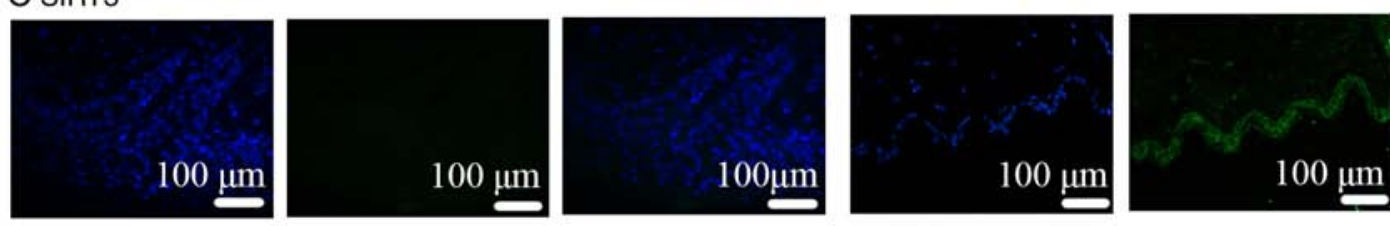

Control group

Fluo488/FITC

Merge

D SIRT4
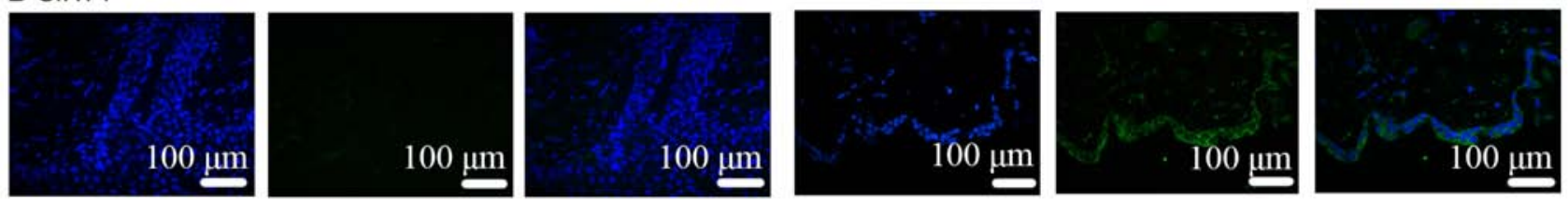

E SIRT5
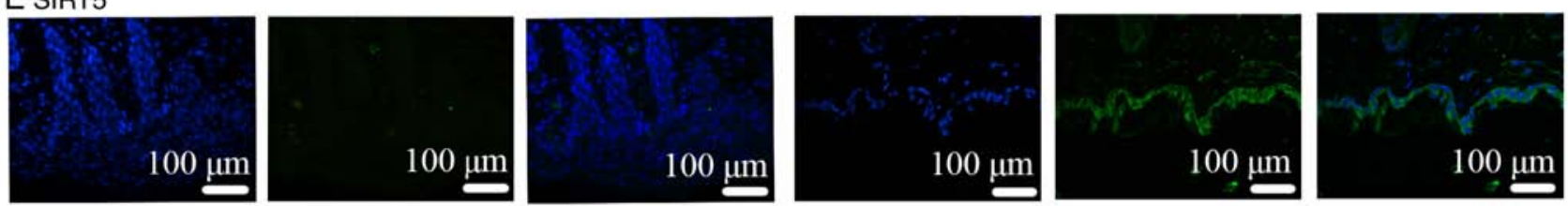

F SIRT6
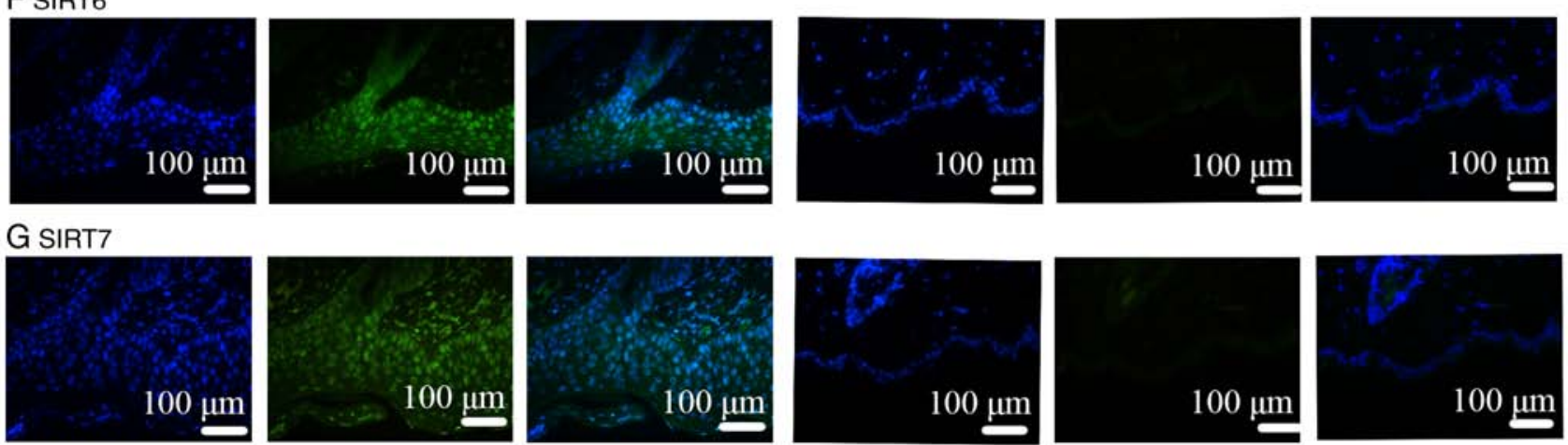

Figure 6. IF in mouse skin lesions. IF in mouse skin lesions were also negative for (A) SIRT1, (B) SIRT2, (C) SIRT3, (D) SIRT4 and (E) SIRT5 antibodies. Lesions were positive for (F) SIRT6 and (G) SIRT7 antibodies. SIRTs were mainly localized in the epithelial layer. IF, immunofluorescence; SIRT, Sirtuin; FITC, fluorescein isothiocyanate.

and arthritis; however, the mechanisms for this action remain unknown $(35,36)$. SIRT1 downregulation occurs in mature psoriasis as the balance of SIRT1 and pro-inflammatory cytokines is lost in immunologically mature psoriatic lesions and cuticle epithelial metabolism disorders due to the bridging effect of SIRT1 between metabolic changes and immune signals (16).

There is a hypothesis that SIRT2 combines with SIRT1 and SIRT6 via NF- $\kappa$ B p65 deacetylation and the modulation of
FOXO3a during oxidative stress, which appears to be a cooperative form of SIRT function in the inflammation process (12).

Mitochondrial SIRTs (SIRT3, SIRT4 and SIRT5) regulate energy metabolism and various homeostatic processes by mediating the post-translational modifications of mitochondrial proteins, including a diverse set of enzymes (7). Among the mitochondrial SIRTs, SIRT3 has a greater number of mitochondrial targets to suppress proliferation capacity, increase fatty acid $\beta$-oxidation, and deacetylate and activate 


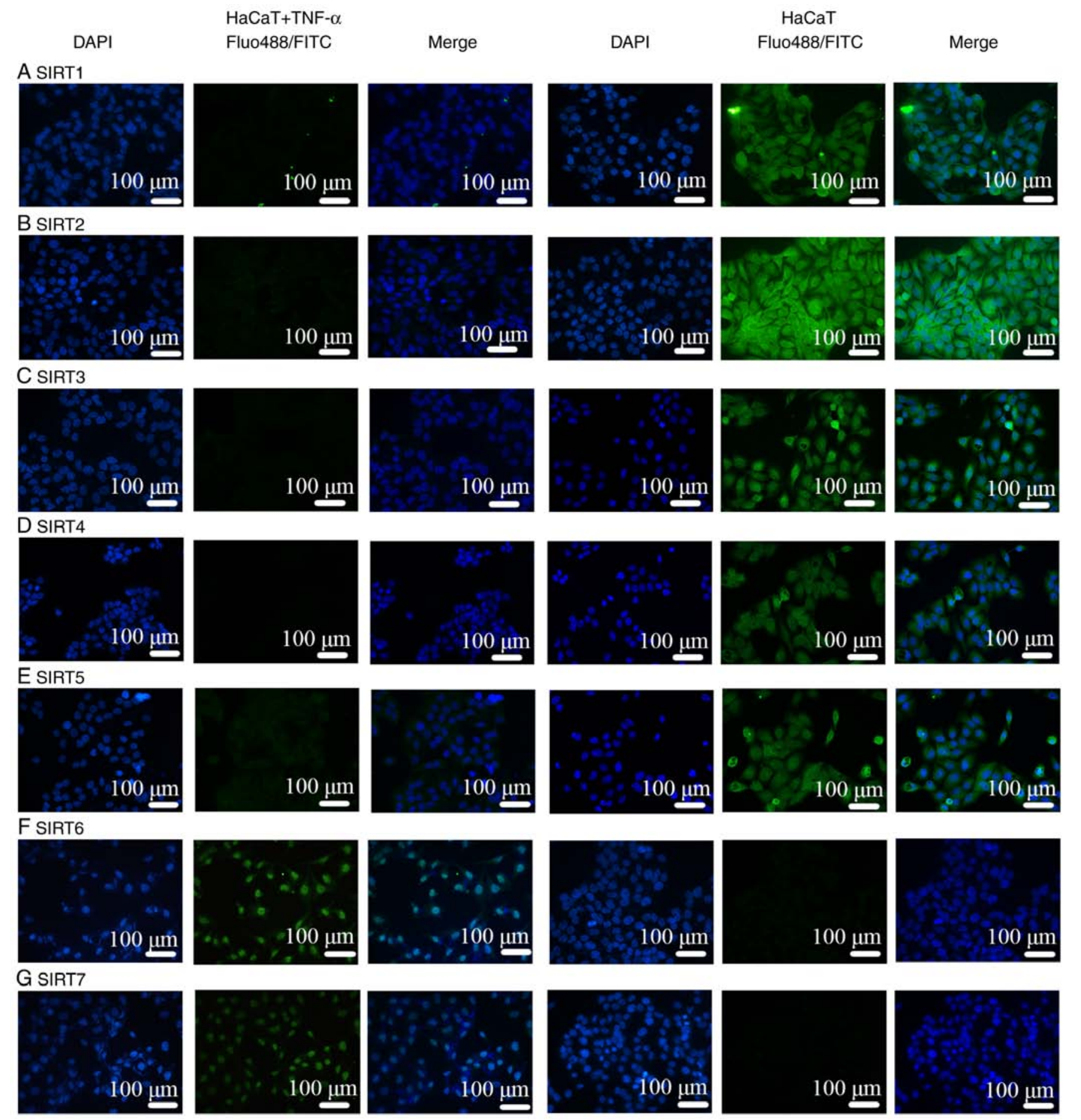

Figure 7. IF in TNF- $\alpha$-stimulated HaCaT cells was negative except for SIRT6 and 7. (A) SIRT1 and (B) SIRT2 were located predominantly in the nucleus and cytoplasm. (C) SIRT3, (D) SIRT4 and (E) SIRT5 were primarily mitochondrial proteins. (F) SIRT6 and (G) SIRT7 were mainly nuclear Sirtuins. IF, immunofluorescence; SIRT, Sirtuin; FITC, fluorescein isothiocyanate.

the key enzymes in the electron transport chain and urea cycle, thereby avoiding the emergence of a diverse set of pathologies (13). The downregulation of SIRT3 is associated with poor prognoses. However, SIRT5 is a more selective deacetylase, modulating, for example, PDH and succinate dehydrogenase, whereas SIRT4 modulates the activity of PDH and GDH only via adenosine diphosphate-ribosyltransferase activity (14). Mitochondrial SIRTs serve a notable function in the regulation of insulin sensitivity through all of the aforementioned pathways. Insulin serves an important function in regulating the body's metabolism of sugar, fats and proteins. When insulin resistance occurs in the body, the physiological effects of insulin on the target tissue are decreased, which may result in pathophysiological alterations in the organism and cause the occurrence of various metabolic diseases (37). Accumulating evidence supports a positive association between psoriasis and insulin resistance $(38,39)$. Furthermore, a number of reports have proposed that hyperglycemia and impaired 


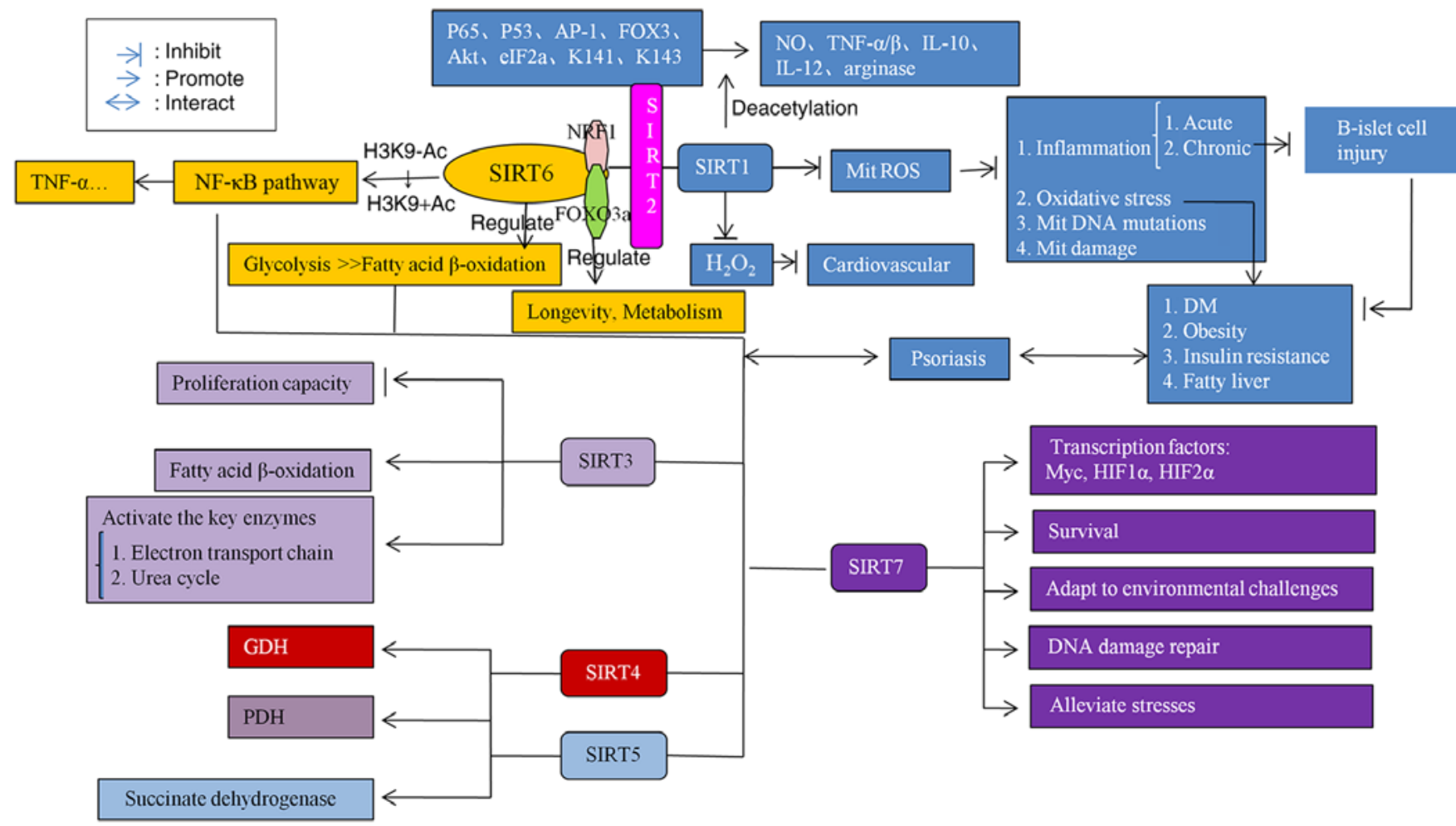

Figure 8. Mechanism of SIRTs in inflammation and metabolism. SIRTs coordinate with each other and serve functions in regulating inflammation and metabolism. When the SIRT level is abnormal, inflammation and metabolic disorders may be caused via a variety of pathways, and then the production

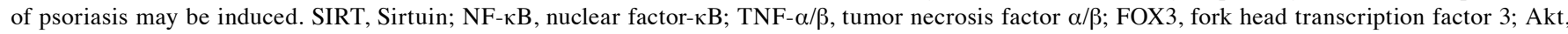
protein kinase B; eIF2a, Eukaryotic translation initiation factor 2A; NO, nitric oxide; IL, interleukin; ROS, reactive oxygen species; Mit, mitochondrial; HIF-1 $\alpha$ hypoxia-inducible factor $1 \alpha$; HIF2 $\alpha$, hypoxia-inducible factor $2 \alpha$; K141, Lys-141; K143, Lys-143.

insulin signaling pathways may be involved in the occurrence of chronic diabetic complications, the glucose utilization of skin keratinocytes, and abnormal skin proliferation and differentiation $(3,40)$.

SIRT7 is a critical regulator of multiple cellular biological processes including transcription, chromatin structure, genomic stability, tumorigenesis, energy homeostasis and cell proliferation. As a pro-survival adaptor molecule, SIRT7 serves a function in regulating specific transcription factors including Myc, hypoxia-inducible factor (HIF)- $1 \alpha$ and HIF2 $\alpha$ via deacetylation (15). The high expression of SIRT7 results in cell proliferation, particularly in metabolically active cells including keratinocytes, and represses the expression of ribosomal proteins to alleviate stress, which allows cells to adapt to environmental challenges and promotes survival. DNA damage repair mediated by SIRT7 may maintain genomic integrity (41).

A summary of the SIRTs mechanism in inflammation and metabolism is presented in Fig. 8.

The results of the present study provide a hypothesis regarding the pathogenesis of psoriasis in a chronic inflammation model. The dynamic equilibrium state of SIRTs under physiological conditions was lost due to a variety of reasons. On one hand, the expression levels of associated nuclear transcription factors were altered, affecting the release of pro-inflammatory factors including TNF- $\alpha$ and metabolic factors including ROS, which function against specific targets that result in inflammatory immune responses and metabolic disorders. On the other hand, multiple cellular biological processes that are mediated by SIRTs, including genome stability, energy homeostasis, cell proliferation, post-translational modifications and insulin resistance, are disrupted, ultimately leading to metabolic diseases and inflammatory diseases. However, further mechanisms require investigation, which will be attempted in the future.

In conclusion, psoriasis is an inflammatory, metabolism-associated disease mediated by the SIRT family. The present study revealed that overexpression of SIRT6 and SIRT7 force the body to adapt to changes in the external environment through various molecular biological mechanisms. However, the downregulation of SIRT1, SIRT2, SIRT3, SIRT4 and SIRT5 is an effect observed at the molecular level of severe psoriasis dermatitis due to an imbalance in the physical state. Thus, SIRT1-SIRT5 agonists and SIRT6 and SIRT7 inhibitors may be novel therapeutic options for psoriasis.

\section{Acknowledgements}

The authors would like to thank Mr. Meiliang Guo (Central Laboratory of Shanghai Sixth People's Hospital Affiliated to Shanghai Jiaotong University, Shanghai, China) for his network support help.

\section{Funding}

The present study was supported by the National Nature Science Foundation of China (grant nos. 81673054 and 81773322) and the Pudong New Area Committee on Health and Family Planning (grant no. PWZxq2017-16). 


\section{Availability of data and materials}

All date used and/or analysed during the present study are available from the corresponding author on reasonable request.

\section{Authors' contributions}

$\mathrm{XF}$ and HD contributed to the conception and design of the study. XF, KY, XY, QM, RS and DY performed the experiments. XF, KY and HD analysed the data. XF, KY, HD and FL interpreted the results of the experiments. XF, KY and HD prepared the figures. XF, KY, QM and HD drafted the manuscript. XF, QM and HD edited and revised the manuscript. All authors read and approved the final manuscript.

\section{Ethics approval and consent to participate}

Patients' written informed consent was obtained and was approved by the Ethics Committee of Shanghai Sixth People's Hospital (registration no. 2018-029). The animal care and experimental procedures were ethically approved by the Animal Welfare Committees of Shanghai Sixth People's Hospital (Shanghai, China; Animal Experiment registration no. DWLL2017-0312).

\section{Patient consent for publication}

Written informed consent was obtained from patients who participated in this study.

\section{Competing interests}

The authors declare that they have no competing interests.

\section{References}

1. Michalek IM, Loring B and John SM: A systematic review of worldwide epidemiology of psoriasis. J Eur Acad Dermatol Venereol 31: 205-212, 2017.

2. Zhao Na: Epidemiologycal analysis on psoriasis vulgaris in a hospital for skin diseases (unpublished PhD thesis). Shandong University, 2011.

3. Napolitano M, Megna M and Monfrecola G: Insulin resistance and skin diseases. ScientificWorldJournal 2015: 479354, 2015.

4. Gu Y and Nordstrom BL: The risk of malignancy among biologic-naive pediatric psoriasis patients: A retrospective cohort study in a US claims database. J Am Acad Dermatol 77: 293-301. e1, 2017.

5. Di Meglio P, Villanova F and Nestle FO: Psoriasis. Cold Spring Harb Perspect Med 4: a015354, 2014.

6. McCormick R, McDonagh B and Goljanek-Whysall K: microRNA-SIRT-1 interactions: Key regulators of adult skeletal muscle homeostasis? J Physiol 595: 3253-3254, 2017.

7. George $J$ and Ahmad N: Mitochondrial sirtuins in cancer: Emerging roles and therapeutic potential. Cancer Res 76: 2500-2506, 2016.

8. Busch F, Mobasheri A, Shayan P, Stahlmann R and Shakibaei M: Sirt-1 is required for the inhibition of apoptosis and inflammatory responses in human tenocytes. J Biol Chem 287: 25770-25781, 2012.

9. Ding RB, Bao J and Deng CX: Emerging roles of SIRT1 in fatty liver diseases. Int J Biol Sci 13: 852-867, 2017.

10. Moynihan KA, Grimm AA, Plueger MM, Bernal-Mizrachi E, Ford E, Cras-Méneur C, Permutt MA and Imai S: Increased dosage of mammalian Sir2 in pancreatic beta cells enhances glucose-stimulated insulin secretion in mice. Cell Metab 2: $105-117,2005$.
11. Gertler AA and Cohen HY: SIRT6, a protein with many faces. Biogerontology 14: 629-639, 2013.

12. Buechler N, Wang X, Yoza BK, McCall CE and Vachharajani V: Sirtuin 2 regulates microvascular inflammation during sepsis. J Immunol Res 2017: 2648946, 2017.

13. Sack MN and Finkel T: Mitochondrial metabolism, sirtuins, and aging. Cold Spring Harb Perspect Biol 4: a013102, 2012.

14. Mathias RA, Greco TM and Cristea IM: Identification of Sirtuin4 (SIRT4) protein interactions: Uncovering candidate acyl-modified mitochondrial substrates and enzymatic regulators. Methods Mol Biol 1436: 213-239, 2016.

15. Kiran S, Anwar T, Kiran M and Ramakrishna G: Sirtuin 7 in cell proliferation, stress and disease: Rise of the seventh sirtuin! Cell Signal 27: 673-682, 2015.

16. Rasheed H, El-Komy M, Hegazy RA, Gawdat HI, AlOrbani AM and Shaker OG: Expression of sirtuins 1, 6, tumor necrosis factor, and interferon-gamma in psoriatic patients. Int J Immunopathol Pharmacol 29: 764-768, 2016.

17. Xie S, Su Z, Zhang B, Ge J, Song S, Sun G, Sun X, Yi L, Wang Y, Sun W, et al: SIRT1 activation ameliorates aldara-induced psoriasiform phenotype and histology in mice. J Invest Dermatol 135: 1915-1918, 2015.

18. Sun J, Han J, Zhu Q, Li Z and Hu J: Camptothecin fails to induce apoptosis in tumor necrosis factor-alpha-treated $\mathrm{HaCaT}$ cells. Pharmacology 89: 58-63, 2012.

19. Cho JW, Lee KS and Kim CW: Curcumin attenuates the expression of IL-1beta, IL-6, and TNF-alpha as well as cyclin E in TNF-alpha-treated HaCaT cells; NF-kappaB and MAPKs as potential upstream targets. Int J Mol Med 19: 469-474, 2007.

20. Xiong H, Xu Y, Tan G, Han Y, Tang Z, Xu W, Zeng F and Guo Q: Glycyrrhizin ameliorates imiquimod-induced psoriasis-like skin lesions in BALB/c mice and inhibits TNF- $\alpha$-induced ICAM-1 expression via NF- $\kappa \mathrm{B} / \mathrm{MAPK}$ in HaCaT cells. Cell Physiol Biochem 35: 1335-1346, 2015.

21. Li R, Wang J, Wang X, Zhou J, Wang M, Ma H and Xiao S: Increased $\beta \operatorname{TrCP}$ are associated with imiquimod-induced psoriasis-like skin inflammation in mice via NF- $\kappa B$ signaling pathway. Gene 592: 164-171, 2016.

22. Livak KJ and Schmittgen TD: Analysis of relative gene expression data using real-time quantitative PCR and the 2(-Delta Delta C(T)) method. Methods 25: 402-408, 2001.

23. Cai Y, Fleming $C$ and Yan J: New insights of T cells in the pathogenesis of psoriasis. Cell Mol Immunol 9: 302-309, 2012.

24. Jeon YJ, Sah SK, Yang HS, Lee JH, Shin J and Kim TY: Rhododendrin inhibits toll-like receptor-7-mediated psoriasis-like skin inflammation in mice. Exp Mol Med 49: e349, 2017.

25. Schwarz G, Boehncke WH, Braun M, Schröter CJ, Burster T, Flad T, Dressel D, Weber E, Schmid H and Kalbacher H: Cathepsin S activity is detectable in human keratinocytes and is selectively upregulated upon stimulation with interferon-gamma. J Invest Dermatol 119: 44-49, 2002.

26. Vachharajani VT, Liu T, Wang X, Hoth JJ, Yoza BK and McCall CE: Sirtuins link inflammation and metabolism. J Immunol Res 2016: 8167273, 2016.

27. Sestito R, Madonna S, Scarponi C, Cianfarani F, Failla CM, Cavani A, Girolomoni G and Albanesi C: STAT3-dependent effects of IL-22 in human keratinocytes are counterregulated by sirtuin 1 through a direct inhibition of STAT3 acetylation. FASEB J 25: 916-927, 2011

28. Torii S, Yamamoto T, Tsuchiya Y and Nishida E: ERK MAP kinase in $\mathrm{G}$ cell cycle progression and cancer. Cancer Sci 97: 697-702, 2006.

29. Kwon TR, Oh CT, Choi EJ, Kim SR, Jang YJ, Ko EJ, Suh D, Yoo KH and Kim BJ: Ultraviolet light-emitting-diode irradiation inhibits TNF- $\alpha$ and IFN-gamma-induced expression of ICAM-1 and STAT1 phosphorylation in human keratinocytes. Lasers Surg Med 47: 824-832, 2015.

30. Ma S, Rao L, Freedberg IM and Blumenberg M: Transcriptional control of K5, K6, K14, and K17 keratin genes by AP-1 and NF-kappaB family members. Gene Expr 6: 361-370, 1997.

31. Harijith A, Ebenezer DL and Natarajan V: Reactive oxygen species at the crossroads of inflammasome and inflammation. Front Physiol 5: 352, 2014.

32. Liu TF, Vachharajani VT, Yoza BK and McCall CE: NAD ${ }^{+}$ dependent sirtuin 1 and 6 proteins coordinate a switch from glucose to fatty acid oxidation during the acute inflammatory response. J Biol Chem 287: 25758-25769, 2012.

33. D'Onofrio N, Servillo L and Balestrieri ML: SIRT1 and SIRT6 signaling pathways in cardiovascular disease protection. Antioxid Redox Signal 28: 711-732, 2018. 
34. Serravallo M, Jagdeo J, Glick SA, Siegel DM and Brody NI: Sirtuins in dermatology: Applications for future research and therapeutics. Arch Dermatol Res 305: 269-282, 2013.

35. Xiao C, Wang RH, Lahusen TJ, Park O, Bertola A, Maruyama T, Reynolds D, Chen Q, Xu X, Young HA, et al: Progression of chronic liver inflammation and fibrosis driven by activation of c-JUN signaling in Sirt6 mutant mice. J Biol Chem 287: 41903-41913, 2012.

36. Hirschey MD, Shimazu T, Jing E, Grueter CA, Collins AM, Aouizerat B, Stančáková A, Goetzman E, Lam MM, Schwer B, et al: SIRT3 deficiency and mitochondrial protein hyperacetylation accelerate the development of the metabolic syndrome Mol Cell 44: 177-190, 2011.

37. Kiran Z, Zuberi BF, Anis D, Qadeer R, Hassan K and Afsar S: Insulin resistance in non-diabetic patients of chronic Hepatitis $\mathrm{C}$. Pak J Med Sci 29: 201-204, 2013.

38. Milčić D, Janković S, Vesić S, Milinković M, Marinković J, Ćirković A and Janković J: Prevalence of metabolic syndrome in patients with psoriasis: A hospital-based cross-sectional study. An Bras Dermatol 92: 46-51, 2017.
39. Liakou AI and Zouboulis CC: Links and risks associated with psoriasis and metabolic syndrome. Psoriasis (Auckl) 5: 125-128, 2015.

40. Owczarczyk-Saczonek AB and Nowicki RJ: Prevalence of cardiovascular disease risk factors, and metabolic syndrome and its components in patients with psoriasis aged 30 to 49 years. Postepy Dermatol Alergol 32: 290-295, 2015.

41. Blank MF and Grummt I: The seven faces of SIRT7. Transcription 8: 67-74, 2017.

(i) $\Theta$ This work is licensed under a Creative Commons Attribution-NonCommercial-NoDerivatives 4.0 International (CC BY-NC-ND 4.0) License. 